Article

\title{
Evaluation of the Sensitivity of Medicane Ianos to Model Microphysics and Initial Conditions Using Satellite Measurements
}

\author{
Albert Comellas Prat ${ }^{1}$, Stefano Federico ${ }^{2, *(\mathbb{D}}$, Rosa Claudia Torcasio ${ }^{2} \mathbb{D}$, Leo Pio D’Adderio ${ }^{2}$, Stefano Dietrich ${ }^{2}$ (D) \\ and Giulia Panegrossi 2 (D) \\ 1 National Research Council of Italy-Institute of Atmospheric Sciences and Climate (CNR-ISAC), \\ Strada Prov.le Lecce-Monteroni, 73100 Lecce, Italy; a.comellas@le.isac.cnr.it \\ 2 National Research Council of Italy_-Institute of Atmospheric Sciences and Climate (CNR-ISAC), \\ Via del Fosso del Cavaliere 100, 00133 Rome, Italy; rc.torcasio@isac.cnr.it (R.C.T.); \\ leopio.dadderio@artov.isac.cnr.it (L.P.D.); s.dietrich@isac.cnr.it (S.D.); g.panegrossi@isac.cnr.it (G.P.) \\ * Correspondence: s.federico@isac.cnr.it
}

\section{check for} updates

Citation: Comellas Prat, A.; Federico, S.; Torcasio, R.C.; D'Adderio, L.P.; Dietrich, S.; Panegrossi, G. Evaluation of the Sensitivity of Medicane Ianos to Model Microphysics and Initial Conditions Using Satellite Measurements. Remote Sens. 2021, 13, 4984. https://doi.org/10.3390/ rs13244984

Academic Editors: Silas Michaelides and Ka Lok Chan

Received: 21 September 2021

Accepted: 6 December 2021

Published: 8 December 2021

Publisher's Note: MDPI stays neutral with regard to jurisdictional claims in published maps and institutional affiliations.

Copyright: (c) 2021 by the authors Licensee MDPI, Basel, Switzerland. This article is an open access article distributed under the terms and conditions of the Creative Commons Attribution (CC BY) license (https:/ / creativecommons.org/licenses/by/ $4.0 /)$.

\begin{abstract}
Tropical-like cyclone (TLC or medicane) Ianos formed during mid-September 2020 over the Southern Mediterranean Sea, and, during its mature stage on days 17-18, it affected southern Italy and especially Greece and its Ionian islands, where it brought widespread disruption due to torrential rainfall, severe wind gusts, and landslides, causing casualties. This study performs a sensitivity analysis of the mature phase of TLC Ianos with the WRF model to different microphysics parameterization schemes and initial and boundary condition (IBC) datasets. Satellite measurements from the Global Precipitation Measurement Mission-Core Observatory (GPM-CO) dual-frequency precipitation radar (DPR) and the Advanced Scatterometer (ASCAT) sea-surface wind field were used to verify the WRF model forecast quality. Results show that the model is most sensitive to the nature of the IBC dataset (spatial resolution and other dynamical and physical differences), which better defines the primary mesoscale features of Ianos (low-level vortex, eyewall, and main rainband structure) when using those at higher resolution ( $25 \mathrm{~km}$ versus $\sim 50 \mathrm{~km}$ ) independently of the microphysics scheme, but with the downside of producing too much convection and excessively low minimum surface pressures. On the other hand, no significant differences emerged among their respective trajectories. All experiments overestimated the vertical extension of the main rainbands and display a tendency to shift the system to the west/northwest of the actual position. Especially among the experiments with the higher-resolution IBCs, the more complex WRF microphysics schemes (Thompson and Morrison) tended to outperform the others in terms of rain rate forecast and most of the other variables examined. Furthermore, WSM6 showed a good performance while WDM6 was generally the least accurate. Lastly, the calculation of the cyclone phase space diagram confirmed that all simulations triggered a warm-core storm, and all but one also exhibited axisymmetry at some point of the studied lifecycle.
\end{abstract}

Keywords: Medicane Ianos; Mediterranean tropical-like cyclones; satellite observations; WRF model; initial conditions; microphysics sensitivity; Hart's phase space diagram

\section{Introduction}

Some densely populated areas in the Mediterranean basin are prone to suffering the impacts of the infrequent but highly destructive tropical-like cyclones (TLCs), also known as Mediterranean hurricanes (medicanes), a local type of storm system that shares some characteristics with tropical cyclones (TCs) [1-3]. Like TCs, medicanes are also intense lowpressure systems with strong surface winds, a calm cloud-free eye, spiraling cloud bands expanding from the center, weak vertical wind shear, and an axisymmetric structure with a warm-core anomaly. In addition, sea-surface heat and moisture fluxes and convective 
latent heat release play important roles in their intensification and maintenance phases. However, they show important differences from TCs such as (1) their reduced size between 100 and $300 \mathrm{~km}$ in diameter, (2) their maximum sustained surface wind speeds never reaching strengths greater than category 1 on the Saffir-Simpson scale (33-42 m/s), (3) the lower minimum sea-surface temperature necessary for their formation at around $15^{\circ} \mathrm{C}$ (compared to $\sim 26^{\circ} \mathrm{C}$ ), (4) the typical duration of their tropical-like phase of a few hours instead of a few days, and (5) their typical origin from an upper-level cold-core trough or cutoff low instead of in a warm barotropic environment [4-8].

Medicanes are associated with serious threats to human life and infrastructure, such as heavy rainfall and flooding, intense wind, lightning, tornadoes, and high waves and storm surge [9-11]. Some studies have explored their time frequency by using modeling and/or observational approaches. While there seems to be consensus that their cyclogenesis frequency lies between one and two per year $[7,12,13]$, there is still significant interannual variability, with high incidence during autumn and winter and a maximum in September. Nevertheless, some researchers have looked into future medicane trends under global warming scenarios, finding that their frequency will slightly decrease, but their duration will increase, and their strength will intensify, thus suggesting that even more violent storms and larger socioeconomic impacts should be expected as decades go by $[14,15]$.

Many authors have focused their efforts on investigating the favorable conditions for TLC formation and evolution, identifying key aspects such as the role of the heat and moisture sea-surface fluxes and latent heating from deep convection, along with other elements, such as the jet stream, the orography, the low-level baroclinicity, and the upper-level potential vorticity (PV) anomaly [16-19]. Yet, the precise mechanisms responsible for medicane genesis and evolution remain unknown, although the currently accepted framework is similar to that for tropical cyclones, which highlights the importance of sea-air energy fluxes and wind within a pre-existing organized cyclonic circulation (known as wind-induced surface heat exchange (WISHE) [20]), although the precursor environment in the Mediterranean is baroclinic. In recent years, however, more attention has been devoted to the action of dry and wet PV anomalies associated with upper-level dry stratospheric air intrusion and low-level condensation latent heat release, respectively, to explain TLC dynamics in the early stage [21,22]. Others have speculated that a different mode of formation may be at play, in which the warm core of the TLC would be the result of a warm air seclusion in the cyclone core [23,24].

The impact of the initial and boundary conditions (IBCs) and the representation of the main sub-grid physical processes in weather models have been examined in some studies of particular medicane cases. Davolio et al. [25] and Chaboureau et al. [18] demonstrated, for the TLC on 26 September 2006 over the Ionian Sea, the high sensitivity of the simulations to the IBCs employed. Miglietta et al. [26] analyzed the influence of the microphysical, cumulus, planetary boundary layer (PBL), and land-surface parameterizations on the WRF model simulations of the same medicane. The study showed that the most critical schemes for a proper TLC forecast were first the microphysics and second the cumulus parameterizations, while the PBL and land-surface schemes were only of minor relevance to the medicane simulations. They also concluded that the variability in the TLC prediction caused by changing the initialization time of the simulations is similar to that of changing the microphysical parameterization scheme. Pytharoulis et al. [27] also tested the model sensitivity to different physical parameterization schemes for the case of Medicane Qendresa (7-8 November 2014), finding somewhat contrarily to Miglietta et al. [26] that the PBL and surface layer schemes had an important influence on the medicane intensity and the cumulus scheme on its track, while the microphysical parameterization impacted mainly the medicane duration. Nonetheless, both studies were in agreement with the seeming inexistence of an optimum combination of physical parameterizations that perform well in all aspects of the medicane forecast. Mylonas et al. [28] studied the sensitivity to varying both the physical parameterizations and the model horizontal resolution, indicating that higher-resolution simulations improved the TLC track and tropical phase state but not 
necessarily the intensity. However, their study showed less spread in TLC intensity and track in the microphysics category than in the other parameterization categories. While employing a fully coupled ocean-atmosphere model, Ricchi et al. [29] evidenced its remarkable sensitivity to the PBL parameterization and IBCs for the case of Medicane Rolf (6-9 November 2011). Ragone et al. [30] simulated the Western Mediterranean climate for a two-decade period, finding that the frequency of medicane formation depended on the cumulus parameterization while the duration of intense medicanes was instead controlled by the microphysics scheme choice.

Altogether, it seems clear that the microphysics parameterization plays a critical role in the correct prediction of medicanes, even though an optimal model configuration is still missing. For the case of tropical cyclones, many studies have shown the relevance of the model microphysics especially for an accurate forecast of their intensity, whereas it only has a minor impact on their track [31-33].

With the advent of the international Global Precipitation Measurement (GPM) mission [34,35], a new set of global precipitation products has become available for meteorological research. The GPM satellite constellation is made up of an ever-changing number of low Earth orbit (LEO) satellites equipped with cross-track and conical passive microwave (PMW) radiometers. The core of the constellation is the NASA/JAXA GPM Core Observatory (GPM-CO), carrying both the dual-frequency precipitation radar (DPR) at Ku/Ka-band and the GPM Microwave Imager (GMI). With the objective of exploiting this new wealth of satellite data, a few studies have explored its usage to analyze and improve the understanding of some of the most extreme heavy precipitation events that occurred in recent years in the Mediterranean region, including TLCs. For instance, Panegrossi et al. [36] demonstrated the value of using precipitation retrievals from the GPM constellation for monitoring the evolution of different severe weather systems, including Medicane Qendresa over the sea. Their subsequent study (Panegrossi et al. [37]) shed more light on the use of the GPM capabilities for monitoring medicane development, in this case for TLC Numa (15-19 November 2017), while Marra et al. [38] showed the skillfulness of a single GPM-CO overpass over a violent hailstorm that developed offshore to capture in fine detail basic characteristics of the exceptional event, which was completely missed by NWP models. Later, Marra et al. [39] documented, with the help of the RAMS weather forecast model, how the GPM PMW radiometer constellation can be successfully exploited to analyze the life cycle (from development to mature phase) of TLC Numa. The authors exploited the GPM-CO DPR overpass, available during Numa's development phase, to provide insights into its microphysical and precipitation structure. In this context, the purpose of this work is to perform an analysis of the sensitivity of the WRF model to different microphysical parameterizations and IBCs for the case of the recent and powerful Medicane Ianos [40], focusing on its final mature stage. The GPM-CO conveniently made an overpass over the system in correspondence of this stage, just a few hours prior to making landfall in the western coast of Greece at its peak of intensity. Because of this, similarly to Marra et al. [39], we employ the insightful observations from the spaceborne platform GPM-CO DPR for the validation of the three-dimensional structure of the simulated medicane during the Ianos TLC phase. In particular, the following characteristics of the TLC were considered from satellite data and compared with model simulations: reflectivity factor (horizontal and vertical distributions and contoured frequency by altitude diagram), rain rate, and integrated water column. To further validate the experiments, we also make use of the sea surface wind data from the Advanced Scatterometer (ASCAT) sensor onboard the MetOp-C satellite as reference data of the wind field.

The remainder of the article is organized as follows: Section 2 describes the datasets and methodology used to carry out the experiments and analyses; Section 3.1 gives an overview of the synoptic situation along with some results regarding columnar hydrometeors, medicane tracking, and the cyclone phase space diagrams; Sections 3.2 and 3.3 present the validation of the simulations against the GPM-CO DPR and ASCAT datasets, respectively; lastly, Section 4 draws the final discussion and conclusions. 


\section{Data and Methodology}

\subsection{Datasets Employed}

The IBCs for the model were obtained from the operational analysis/forecast cycle at 12:00 a.m. UTC 17 September 2020 from the European Centre for Medium-Range Weather Forecasts (ECMWF) Integrated Forecast System (IFS) at $0.25^{\circ}$ horizontal resolution, and from the US National Weather Service (NWS) Global Forecast System (GFS) forecasts at $0.5^{\circ}$ horizontal resolution.

For the examination of the medicane experiments, we used the following spaceborne observational platforms: (1) the 3D corrected reflectivity data at Ku-band from the GPMCO DPR, available over a $245 \mathrm{~km}$ wide swath, with an approximate horizontal resolution of $5 \mathrm{~km}$ (at nadir) and $250 \mathrm{~m}$ range resolution [34]. In particular, the overpass at 10:31 p.m. UTC 17 September 2020 over the Ionian Sea was used to evaluate the simulated reflectivity factor, integrated rainwater and solid hydrometeor (snow and graupel) contents, and instantaneous surface precipitation rate as reported in the 2A-DPR product [41]; (2) the coastal ocean surface wind product from the Advanced Scatterometer (ASCAT), with sampling resolution of $12.5 \mathrm{~km}$ and effective resolution of $25 \mathrm{~km} \mathrm{[42].} \mathrm{The} \mathrm{MetOp-C}$ satellite overpass that captured TLC Ianos at 7:11 p.m. UTC was used to verify the simulated near-surface winds.

\subsection{Methodology}

The Weather Research and Forecasting Model (WRF-ARW version 4.1.2 [43]) was used to perform the simulations. The domain had horizontal dimensions of $530 \times 530$ grid points (Figure 1) and 60 hybrid sigma-pressure vertical levels, with a model top of $40 \mathrm{hPa}$. The time step was $15 \mathrm{~s}$, and the horizontal resolution was $3 \mathrm{~km}$. All simulations were initialized at 12:00 p.m. UTC 17 September 2020 and ended $12 \mathrm{~h}$ later at 12:00 a.m. UTC 18 September 2020, while the first $6 \mathrm{~h}$ were considered as spin-up and only the last $6 \mathrm{~h}$ were used as forecast. The boundary conditions were updated every $3 \mathrm{~h}$.

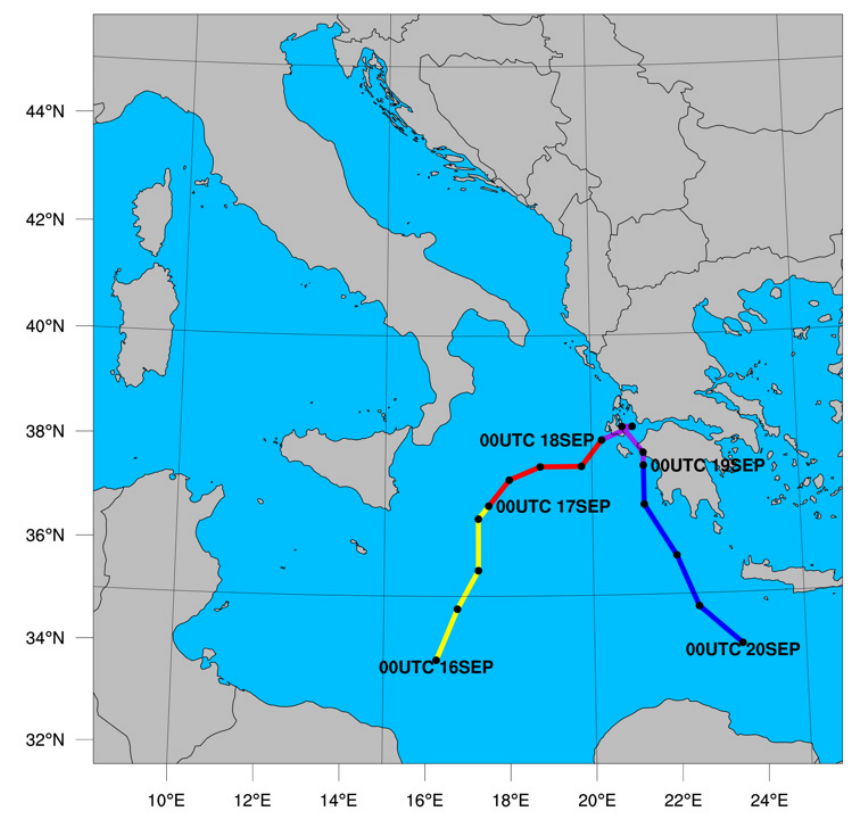

Figure 1. WRF model domain employed in this study, consisting of 530 by 530 grid points with horizontal spacing of $3 \mathrm{~km}$, along with the Medicane Ianos track calculated every $6 \mathrm{~h}$ from the ERA-5 reanalysis.

Four microphysics parameterizations of varying degrees of complexity were chosen to carry out the sensitivity study: the single-moment WSM6 [44], the double-moment 
warm rain only WDM6 [45], the double-moment rain and ice new Thompson [46], and the double-moment rain and ice/snow/graupel Morrison [47] schemes.

The other physical parameterizations used were the Yonsei University scheme for the boundary layer [48], the revised MM5 Monin-Obukhov scheme for surface layer physics [49], the Noah land surface model [50] for surface processes, and the Dudhia [51] and RRTM [52] for short- and longwave radiation schemes, respectively. No cumulus parameterization was activated, and we assumed that convection was explicitly represented at $3 \mathrm{~km}$ horizontal resolution.

With the aim of objectively measuring the tropical-like characteristics of the simulated cyclone, the Hart three-dimensional cyclone phase space [53] was calculated for each simulation. The phase space was represented by two diagrams: the first featured the lower level $(900-600 \mathrm{hPa})$ thermal wind $\left(-\mathrm{V}_{\mathrm{T}}^{\mathrm{L}}\right)$ against the upper level $(600-300 \mathrm{hPa})$ thermal wind $\left(-\mathrm{V}_{\mathrm{T}} \mathrm{U}\right)$, highlighting the depth (shallow/deep) and the thermal anomaly (cold/warm) of the low pressure system's core; the second informed us about its thermal symmetry by showing the 900-600 hPa storm-relative thickness symmetry (B) against the lower level thermal wind, evidencing its symmetric/non-frontal or asymmetric/frontal structure. The thermal wind was calculated as the vertical derivative of the geopotential height perturbation (the difference between the maximum and minimum values) every $50 \mathrm{hPa}$ within a radius of $200 \mathrm{~km}$ from the minimum mean sea-level pressure (MSLP) center. While Hart [53] employed a radius of $500 \mathrm{~km}$ adequate for tropical cyclone dimensions, a radius of $200 \mathrm{~km}$, in line with other authors [19,26,54], was used to account for the smaller TLC spatial scales (ranging from 50 to $200 \mathrm{~km}$ [55]). The symmetry parameter B was calculated as the difference between the mean 900-600 hPa layer thickness of the right and left semicircles with respect to the trajectory of the system. We performed the calculation every 10 degrees and picked the highest value of B to remove any chance of inaccuracy due to trajectory noise, similarly to Mylonas et al. [28]. Hurricanes and medicanes are generally considered to have undergone tropical transition when they become thermally axisymmetric and have a deep warm core, which is objectively determined by simultaneously satisfying that the parameter B falls below $10 \mathrm{~m}$ and that both the lower- and the upper-level thermal winds are positive.

\subsection{Synoptic Overview}

The precursor of Medicane Ianos was an upper-level cutoff low that formed over the western Mediterranean around the 8-9 September and slowly moved eastward toward northern Tunisia and the Strait of Sicily. Then, on 14-15 September, as it emerged over the Gulf of Sidra, due to a stratospheric dry air intrusion with high vorticity values (Figure 2c) and anomalously high $\left(\sim+1.5^{\circ} \mathrm{C}\right)$ sea-surface temperatures of $\sim 27-28^{\circ} \mathrm{C}$ (Figure $\left.2 \mathrm{~d}\right)$ [56], a surface low-pressure system quickly developed with a minimum pressure around $1010 \mathrm{hPa}$. On 16 September, it further deepened and intensified. Wind speeds up to $25 \mathrm{~m} \cdot \mathrm{s}^{-1}$ were measured by ASCAT sensors (onboard MetOp satellites) around the cyclone's circulation center. From 17 September, the system showed a clear mid-level warm core (Figure 2a) and spiraling cloud bands, especially to the northern side of a well-defined vortex, with a distinct cloud-free eye. Locally large precipitation amounts were recorded in the Calabria region of Southern Italy [57]. It continued to deepen both its surface pressure and its mid-level warm core as it slowly moved east-northeastward toward the Ionian Greek islands (Figure 2b) and Greece mainland, where it made landfall around 3:00 a.m. UTC 18 September. The medicane peak intensity was evidenced by a 995 hPa MSLP minimum and $33 \mathrm{~m} \cdot \mathrm{s}^{-1}$ ASCAT surface winds, thus becoming classifiable as a minor category 1 hurricane on the Saffir-Simpson scale. Just a few hours earlier, the GPM-CO satellite made an overpass over the Ionian Sea at 10:31 p.m. UTC 17 September, providing valuable DPR measurements for analysis of the mature phase of Ianos's TLC lifecycle. The medicane then crossed Greece on 18-19 September, causing several human casualties and widespread disruption due to wind damage, heavy rainfall, and extensive flooding in the western and central regions (e.g., a total of $228 \mathrm{~mm}$ in the Ionian island of Ithaki or the maximum 
amount of $317 \mathrm{~mm}$ in Pertouli, Central Greece [40]). In some areas, the mean annual precipitation was exceeded in a span of $48 \mathrm{~h}$. On the following days, Ianos weakened considerably while it moved south-southeastward and finally dissipated over the northern coast of Egypt on 21 September.

a)

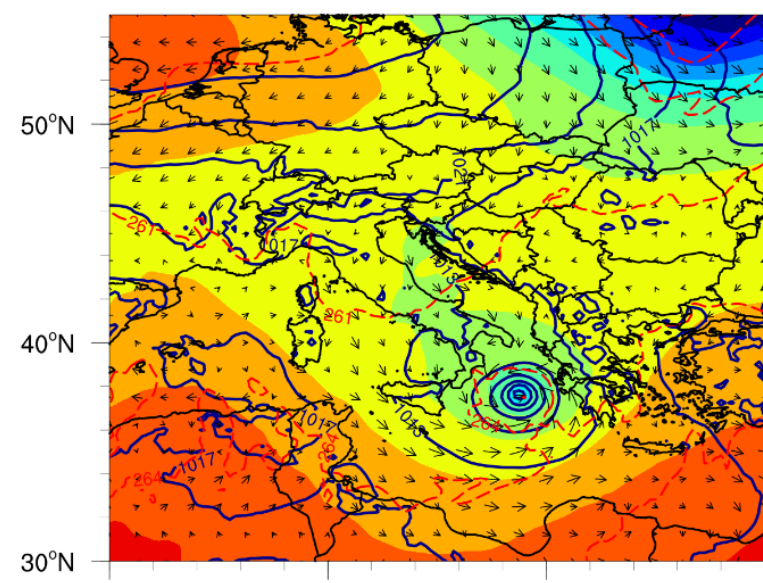

b)

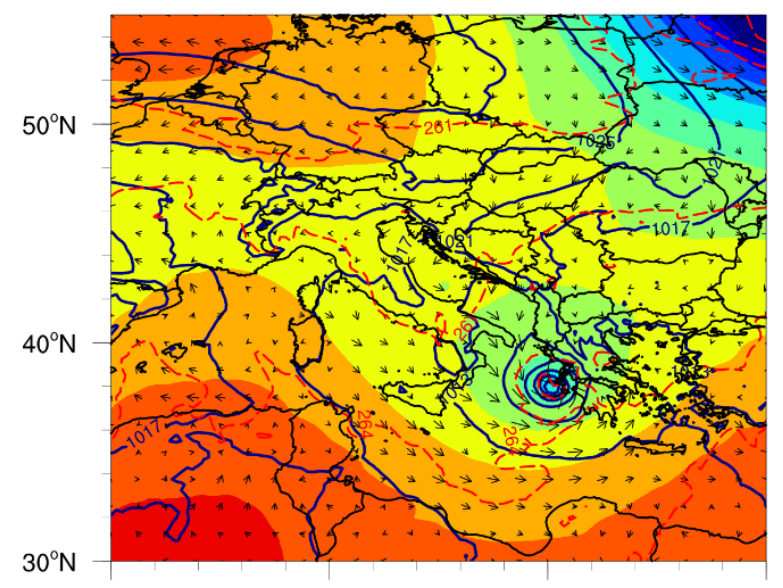

$30^{\circ} \mathrm{N}$
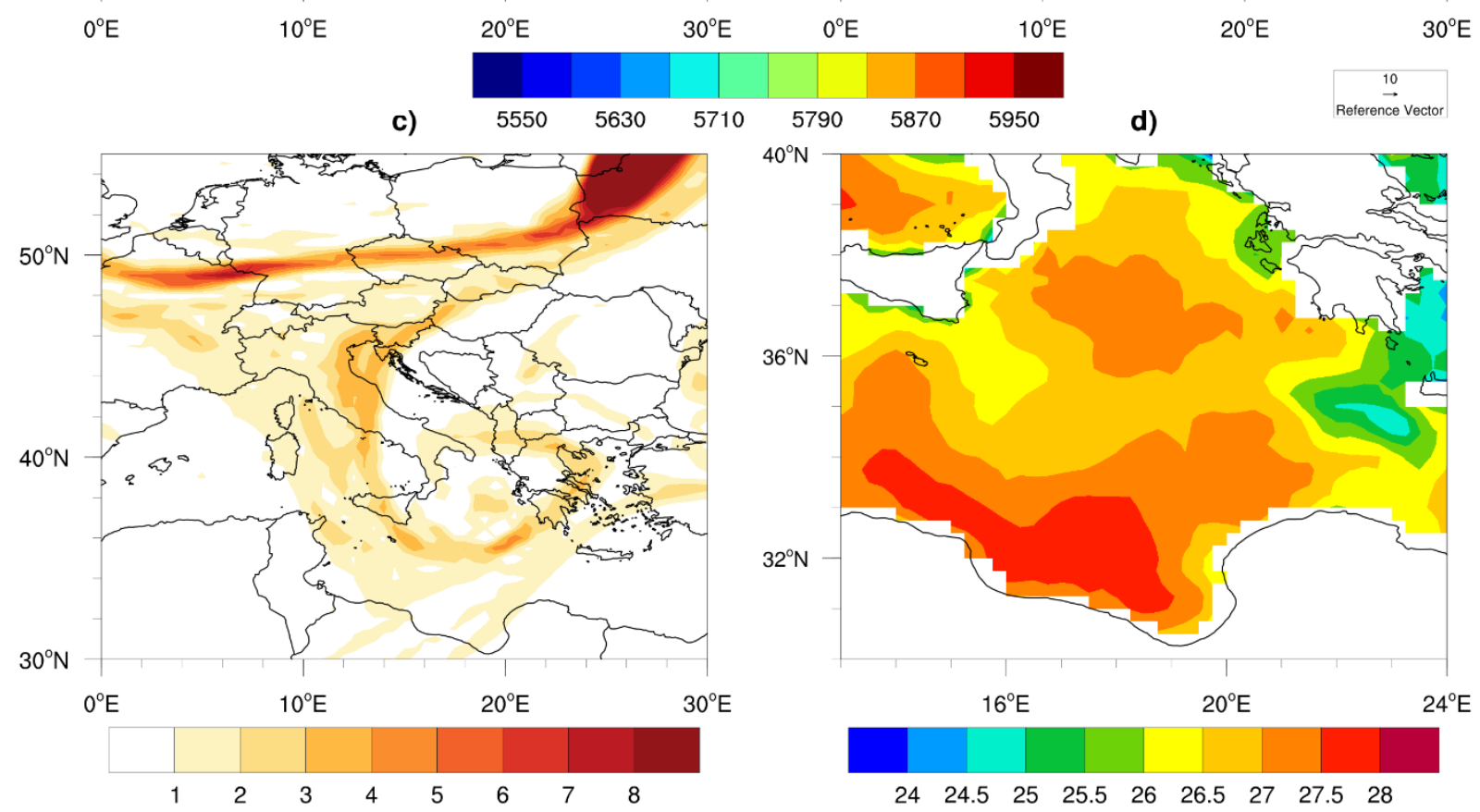

Figure 2. The ECMWF synoptic setups at 12:00 p.m. UTC 17 September 2020 (a) and 12:00 a.m. UTC 18 September 2020 (b), the ECMWF $300 \mathrm{hPa}$ potential vorticity at 12:00 p.m. UTC 17 September 2020 (c), and the ERA-5 sea-surface temperature at 12:00 a.m. UTC 16 September 2020 (d). In (a,b), the $500 \mathrm{hPa}$ geopotential height filled contours are in $\mathrm{m}$, the $500 \mathrm{hPa}$ temperature contours (dashed red lines) are drawn every $3 \mathrm{~K}$, the mean sea-level pressure contours (solid dark-blue lines) are shown every $4 \mathrm{hPa}$, and the $10 \mathrm{~m}$ wind field's (black arrows) reference vector is in $\mathrm{m} \cdot \mathrm{s}^{-1}$. In (c), the units are potential vorticity units (PVU: $10^{-6} \mathrm{~K} \cdot \mathrm{m}^{2} \cdot \mathrm{kg}^{-1} \cdot \mathrm{s}^{-1}$ ); in (d). the units are degrees Celsius $\left({ }^{\circ} \mathrm{C}\right)$.

\section{Results}

\subsection{Storm Evolution and Cyclone Phase Space Analysis}

In Figure $3 a, b$, we can observe the timeseries of the integrated rainwater and frozen hydrometeor (snow + graupel) content mean values, respectively, within a radius of $100 \mathrm{~km}$ from the minimum pressure center every half-hour as simulated by the different microphysics experiments. On one hand, all simulations initialized with GFS showed a significant downward trend in rainwater content, with lower values at the end of the simulations 
than at $6 \mathrm{~h}$ after the start; on the other hand, those initialized with ECMWF data showed a generally steady evolution (Figure 3a). If we look at the integrated frozen hydrometeor content, we can appreciate again a decreasing trend in the GFS simulations and overall stable evolutions for the ECMWF simulations. For both global model groups of experiments, the Thompson scheme was the one that predicted the highest amounts of snow and graupel (Figure 3b); it is interesting to note that this scheme predicted much smaller (larger) amounts of pristine ice (snow) columnar contents in comparison to the others (not shown). When comparing these predicted variables at 10:30 p.m. UTC to the GPM-CO DPR retrieval at 10:31 p.m. UTC 17 September, we can find that (i) the observed mean integrated rainwater content for the area of $100 \mathrm{~km}$ radius from the cloud-free eye was $1.24 \mathrm{~mm}$, falling within the range of values of the ECMWF-based experiments ( 0.9-1.3 $\mathrm{mm})$, whereas those with GFS data varied between roughly 0.4 and $0.65 \mathrm{~mm}$, and (ii) the observed integrated frozen hydrometeor areal mean was $0.29 \mathrm{~mm}$, only very slightly overestimated by WSM6 and WDM6 GFS at $0.30-0.40 \mathrm{~mm}$, while all other simulations largely overestimated it with values between $\sim 1.2 \mathrm{~mm}$ (Morrison GFS) and $2.45 \mathrm{~mm}$ (Thompson ECMWF). Therefore, it is noticeable that, for this case study, the variability among the simulations with each global model was larger for the integrated frozen hydrometeor content than for the rainwater content.

a)

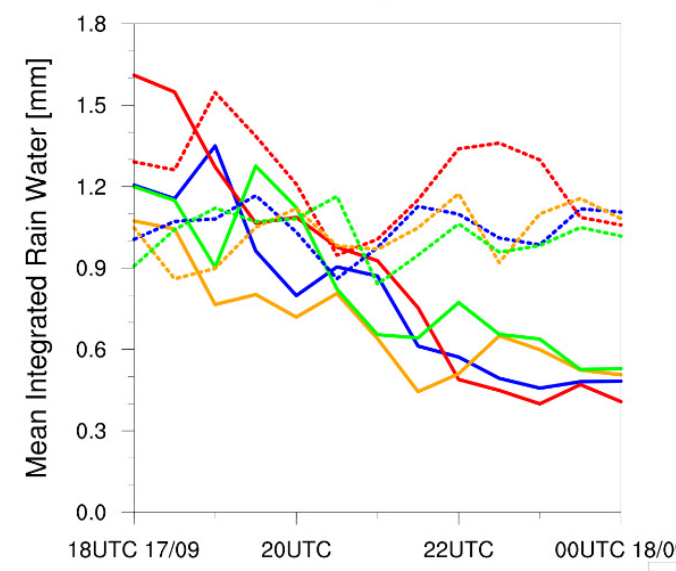

b)

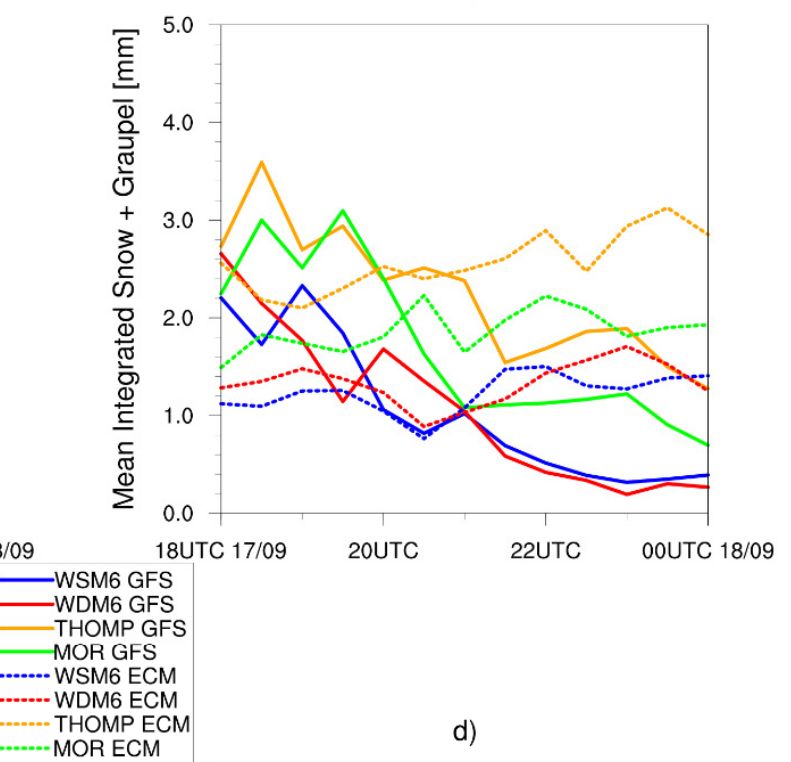

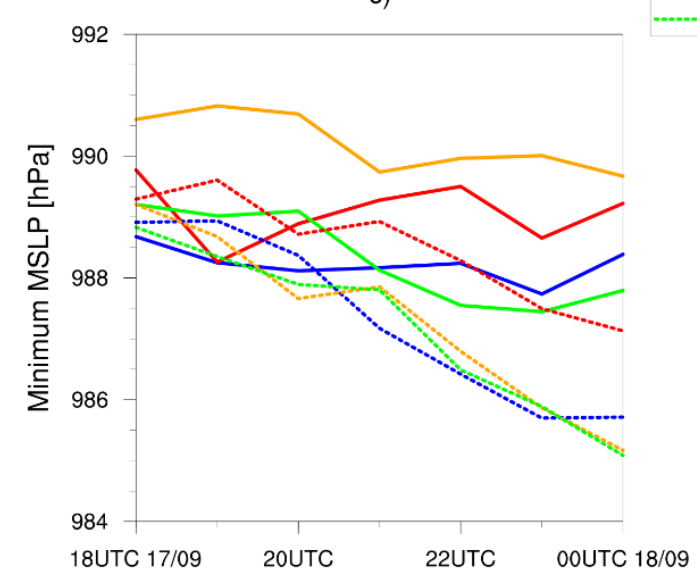

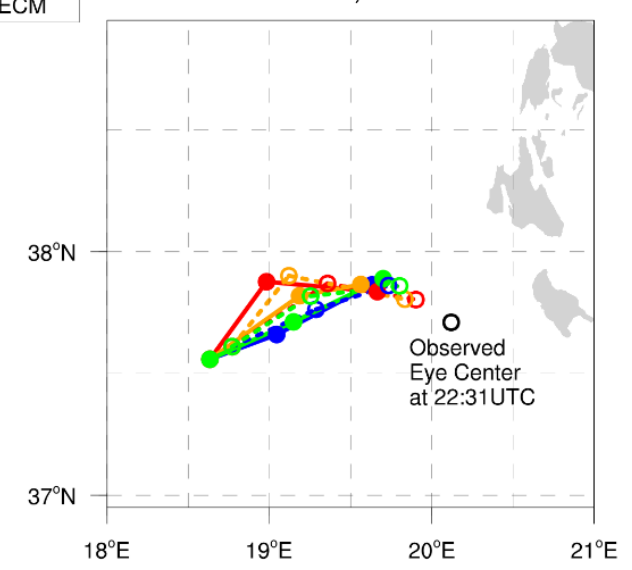

Figure 3. Timeseries of the simulations' mean integrated rainwater content (a) and mean integrated solid hydrometeor content (b) for an area of radius $100 \mathrm{~km}$ around the minimum MSLP center, the evolution of minimum MSLP (c), and the storm tracks $(\mathrm{d})$ with dots indicating the MSLP position every $6 \mathrm{~h}$. For $(\mathbf{a}-\mathbf{c})$, the initial $6 \mathrm{~h}$ of simulation spin-up are not shown for clarity. 
The evolution of the minimum mean sea-level pressure (MSLP) and the storm tracks with the MSLP positions every $6 \mathrm{~h}$ are shown in Figure $3 c, d$, respectively. The minimum MSLP evolution evidences that all experiments were able to trigger the system's intensification with time (Figure 3c), albeit with some differences. At the same time, it is important to note that we could not find an official best track and intensity estimation for Medicane Ianos; nevertheless, data from different reports agreed with the time of maximum strength being around 3:00 a.m. UTC 18 September with a minimum MSLP between 992 and $995 \mathrm{hPa}$. The ECMWF-based simulations predicted overall lower pressure and a steeper fall during the last few hours of the simulation (i.e., from about 8:00 p.m. UTC 17 September onward) than those GFS-based, which predicted more subtle intensifications and more spaced throughout the last $6 \mathrm{~h}$. The Thompson GFS experiment seemed the most realistic in terms of the final decrease of minimum MSLP according to available observations. Regarding the storm tracks, the variation among the different experiments was generally small, and their northeastward motion direction coincided with observational reports and with the global model reanalysis (not shown). Overall, both for each parameterization pair and for each global model initial setup, the distance between their respective minimum MSLP positions at 6:00 p.m. UTC 17 September and 12:00 a.m. UTC 18 September was never larger than $\sim 30-40 \mathrm{~km}$.

Additionally, it becomes clear, looking at the variability of the minimum MSLP evolutions and at the medicane tracks among the different experiments, that the choice of the microphysics scheme had a much bigger impact on the former than on the latter.

Since we were focused on the mature stage of Medicane Ianos, we performed a brief exploration of the tropical-like characteristics of the simulated storm by calculating its 3D cyclone phase space diagrams, which are shown in Figure 4 at intervals of $6 \mathrm{~h}$. In Figure 4a,c, all experiments clearly show a deep warm core throughout the whole simulation. The warm core deepened with time over the whole column for the simulations with ECMWF data, while it tended to lose strength in the lower levels but deepened in the upper levels for the simulations with GFS. Figure $4 b$, d exhibit the thermal symmetry parameter $B$ of the lower levels against the thermal wind, with $B=10 \mathrm{~m}$ considered as the maximum theoretical threshold for categorizing a tropical cyclone/medicane as axisymmetric. Almost all simulations were able to trigger an axisymmetric TLC in at least one of the considered timesteps. The experiments with GFS all started with $\mathrm{B} \approx 10 \mathrm{~m}$ at 12:00 p.m. UTC 17 September and ended at 12:00 a.m. UTC 18 September with B between 10 and $12 \mathrm{~m}$, thus transitioning from axisymmetry at the beginning to asymmetric status at the middle and end points. On the other hand, all ECMWF-based experiments started from $\mathrm{B} \approx 15 \mathrm{~m}$ and then diverged into two groups; WDM6 and Thompson reached clear axisymmetry eventually (i.e., B values of $\sim 4 \mathrm{~m}$ and $\sim 7 \mathrm{~m}$, respectively), whereas WSM6 and Morrison, on the other hand, reached their lowest $B$ values of $\sim 10 \mathrm{~m}$ and $\sim 11.5 \mathrm{~m}$ at 6:00 p.m. UTC 17 September and 12:00 a.m. UTC 18 September, respectively. 
a)

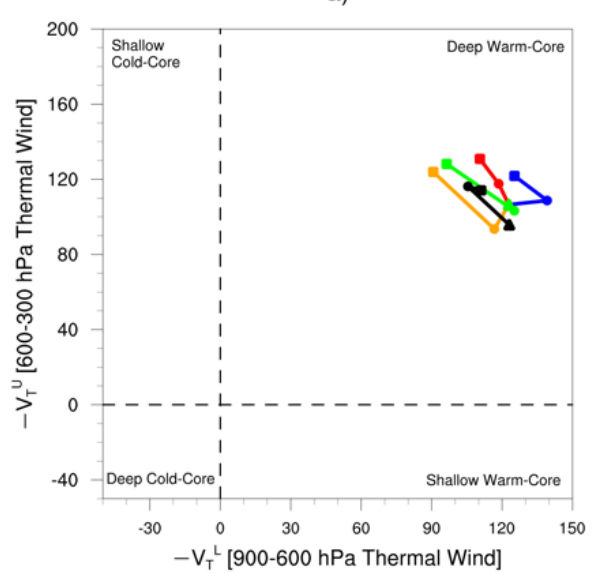

c)

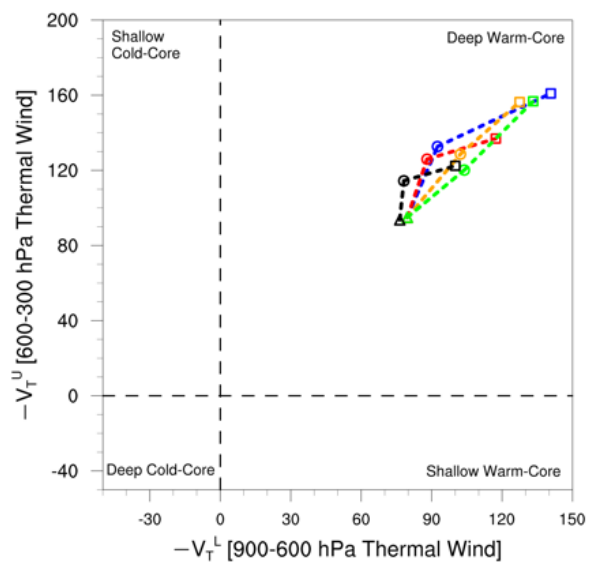

b)

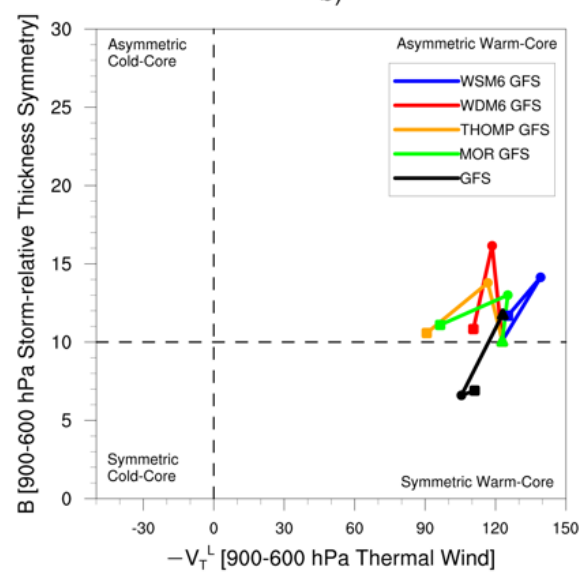

d)

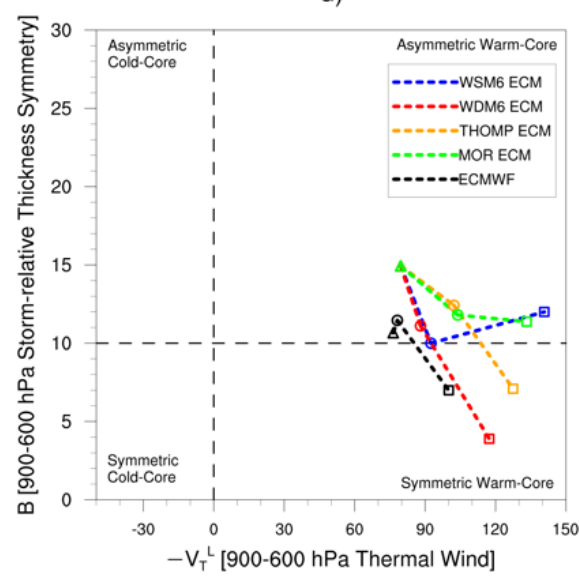

Figure 4. Cyclone phase space diagrams showing the thermal structure $(\mathbf{a}, \mathbf{c})$ and symmetry $(\mathbf{b}, \mathbf{d})$ for the experiments performed with GFS $(\mathbf{a}, \mathbf{b})$ and ECMWF $(\mathbf{c}, \mathbf{d})$ data. Triangles denote the position at 12:00 p.m. UTC 17 September 2020, circles denote the position at 6:00 p.m. UTC, and squares denote the position at 12:00 a.m. UTC 18 September 2020.

Altogether, all experiments except Morrison ECMWF were able to forecast a TLC with axisymmetric status, according to Hart's definition, in at least one of the three timesteps considered for each experiment, and the same was true for the two global model datasets, both of which predicted clear axisymmetry by 12:00 a.m. UTC 18 September. However, the GFS-based experiments attained axisymmetry only at the start and remained asymmetric for the rest of integration time, whereas, among the ECMWF-based experiments, the tendency was the opposite; all started with asymmetry but half of them were able to reach deep axisymmetric status, while the other half only exhibited mild or no axisymmetry at all.

\subsection{Examination of the Simulations with GPM-CO DPR}

Just a few hours before the medicane reached its peak intensity and made landfall in mainland Greece, the DPR instrument onboard GPM-CO was able to capture the Ianos 3D mature stage structure over the Ionian Sea as it was approaching the Greek islands. In Figure $5 \mathrm{a}-\mathrm{h}$, we can see the radar reflectivity factor at $5 \mathrm{~km}$ height as predicted by different WRF microphysical schemes at 10:30 p.m. UTC 17 September. Figure $5 i$ shows the DPR Ku-band corrected reflectivity at $5 \mathrm{~km}$ at 10:31 p.m. UTC. From the observations, the cloud-free eye can be appreciated with spiraling rainbands around the eyewall and extending over parts of the Greek islands of Zakynthos and Kefalonia. Its highest intensity of $44.4 \mathrm{dBZ}$ was located at the southwestern portion of the eyewall, with the main rainband extending north/northeast from the eyewall and the outer weaker band of more stratiform 
rain extending north up to southern Albania. The ECMWF-based simulations were able to position the eyewall and the rainbands to the northwest of the eye more accurately and visibly in better agreement with the observations (Figure 5i). On the other hand, the GFS-based experiments successfully produced the southwestern eyewall but failed in its remaining portions and outer rainbands, which were located too far away near the Apulian peninsula, with large overestimations of the stratiform precipitation. Furthermore, Thompson and Morrison ECMWF-based simulations predicted a well-defined and relatively closed eye, while WSM6 and WDM6 showed lower performance in this regard.

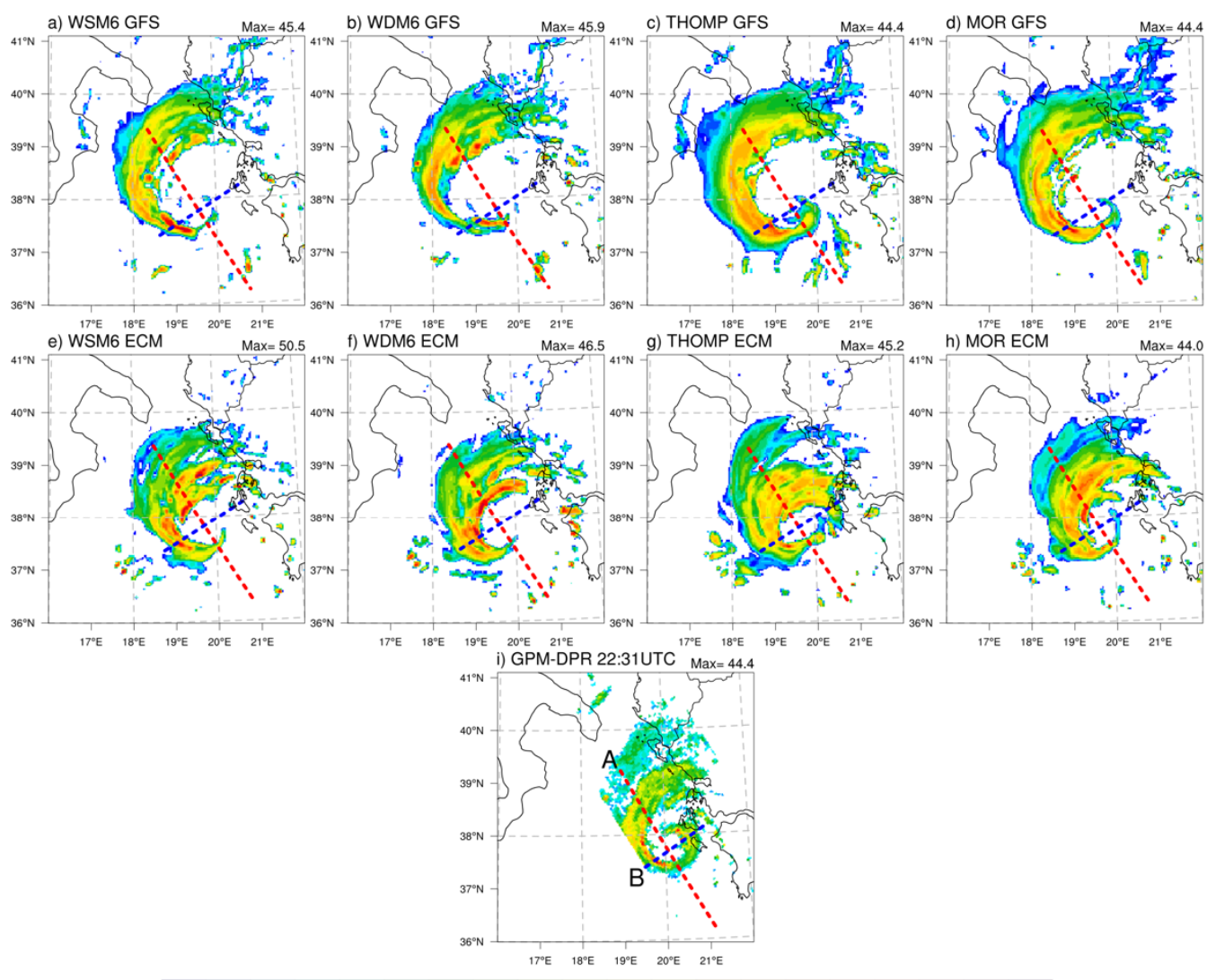

$\begin{array}{lllllllllllllllllll}12 & 14 & 16 & 18 & 20 & 22 & 24 & 26 & 28 & 30 & 32 & 34 & 36 & 38 & 40 & 42 & 44 & 46 & 48\end{array}$

Figure 5. Radar reflectivity factor (dBZ) at $5 \mathrm{~km}$ height at 10:30 p.m. UTC 17 September 2020 for all simulations (a-h) and as observed by the GPM-CO DPR overpass at 10:31 UTC p.m. (i) (the Ku-band corrected reflectivity is shown). The red and blue dashed lines intersect at the minimum MSLP center and indicate the location of the perpendicular vertical cross-sections shown in Figures 6 and 7. 


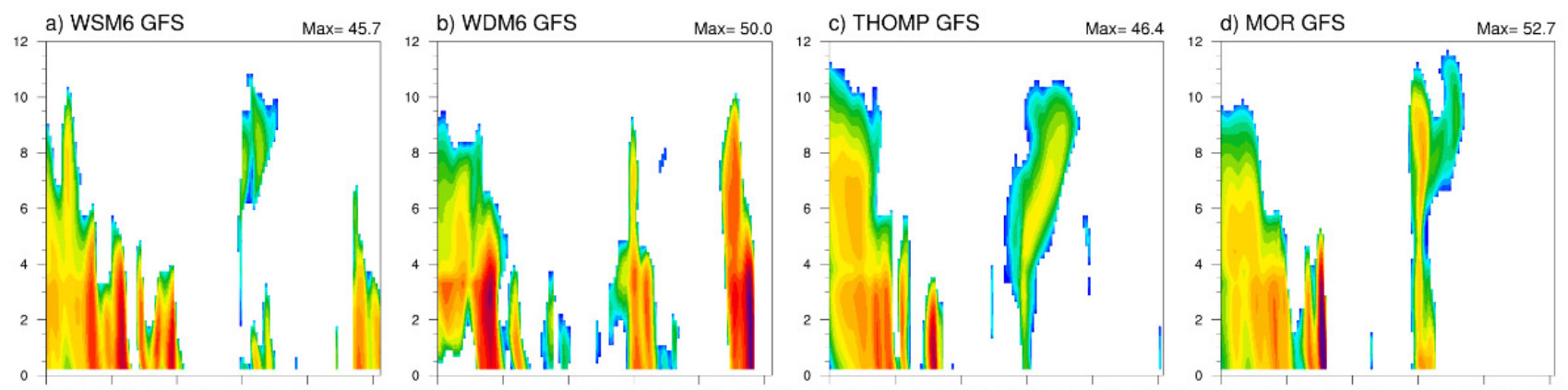

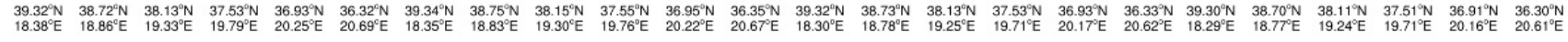

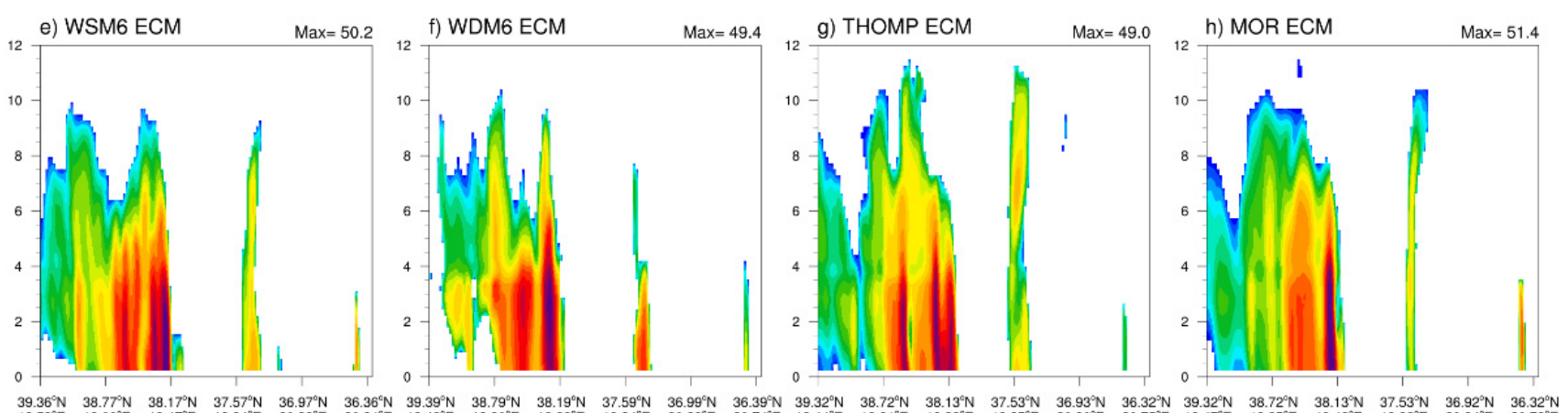

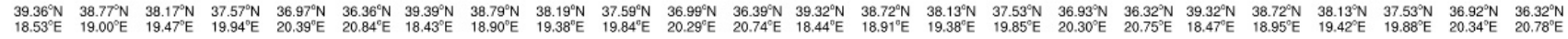

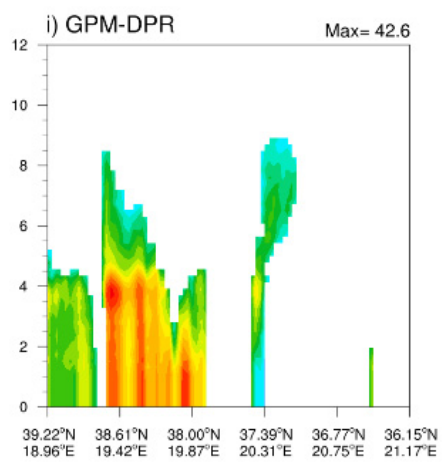

$\begin{array}{lllllllllllllllllll}12 & 14 & 16 & 18 & 20 & 22 & 24 & 26 & 28 & 30 & 32 & 34 & 36 & 38 & 40 & 42 & 44 & 46 & 48\end{array}$

Figure 6. Vertical cross-sections in the NW-SE direction of Ku-band radar corrected reflectivity (dBZ) at 10:30 p.m. UTC 17 September 2020 for all simulations (a-h) and as observed by the GPM-CO DPR overpass at 10:31 p.m. UTC (i). Their relative location is indicated in Figure $5 \mathrm{i}$ by the red dashed line $A$. The vertical axes are in $\mathrm{km}$.

While all the other experiments tended to overestimate the reflectivity in most areas of the eyewall and outer bands, the Thompson ECMWF simulation (Figure 5g) was the only one that succeeded in placing part of the eastern eyewall over Kefalonia and accurately predicting the reflectivity peak in the southwestern quadrant, despite creating a more elongated eye in the SW-NE direction. 

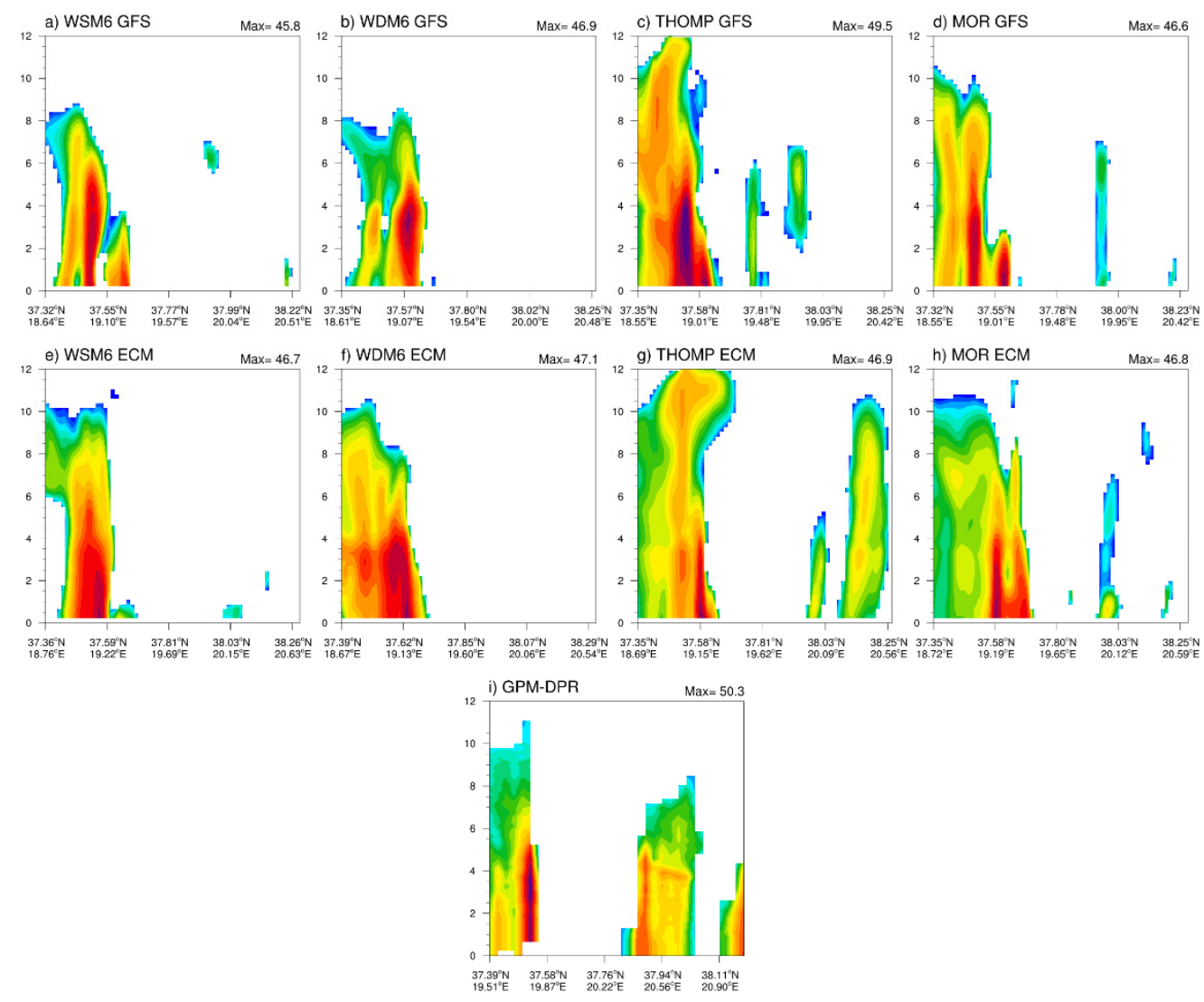

$\begin{array}{lllllllllllllllllll}12 & 14 & 16 & 18 & 20 & 22 & 24 & 26 & 28 & 30 & 32 & 34 & 36 & 38 & 40 & 42 & 44 & 46 & 48\end{array}$

Figure 7. Vertical cross-sections in the SW-NE direction of Ku-band radar corrected reflectivity (dBZ) at 10:30 p.m. UTC 17 September 2020 for all simulations (a-h) and as observed by the GPM-CO DPR overpass at 10:31 p.m. UTC (i). Their relative location is indicated in Figure $5 \mathrm{i}$ by the blue dashed line B (note that panel (i) is not centered around the TLC's eye center but the other panels are). The vertical axes are in $\mathrm{km}$.

To gain some insight into the TLC structure, Figure 6 reports the vertical cross-sections of the model prediction and the DPR Ku-band reflectivity factor for the NW-SE segment of $400 \mathrm{~km}$ length across the system, as indicated by the red dashed line A in Figure 5i, centered at the TLC's minimum MSLP and cloud-free eye centers, respectively. The DPR observations (Figure 6i) showed a reflectivity peak of $42.6 \mathrm{dBZ}$ around a height of $4 \mathrm{~km}$ in the main rainband to the northwest of the eye, an area of intense precipitation at $0-1 \mathrm{~km}$ in the eyewall, and weaker intensities elsewhere, with clouds reaching maximum heights of 8-9 km. The DPR reflectivity profile was coherent with a stratiform precipitation, with the reflectivity peak in correspondence with the bright band located around a height of $3.5-4 \mathrm{~km}$ (slightly more elevated in the central region due to the warm-core anomaly). All WRF simulations tended to overestimate both the intensity and the vertical extent of the reflectivity factor field, triggering exaggeratedly strong convective updrafts, and most cloud tops attained altitudes of 10-11 km. Nevertheless, the ECMWF-based experiments proved to be more skillful and showed better agreement with the DPR profile in terms of main features of the system's mesoscale organization, succeeding in accurately creating the two sides of the eyewall, distinguishing the main intense rainband from the outer band of weaker rain to the northwest, and even the narrow and light precipitation area to the southeastern side.

Most GFS-based simulations, instead, realistically represented the southeastern portion of the eyewall, but they tended to underestimate the northwestern side; furthermore, they were not able to predict the main rainband with sufficient consistency and homogeneity (or they did, but placed it too far to the northwest). These results show the important role 
of IBCs in the simulation of the characteristics of Ianos. The difference between ECMWF and GFS models and data assimilation systems, as well as the different horizontal and vertical resolutions of the global models, had a role in determining the WRF sensitivity to IBCs. It was not possible to separate these factors, with the global model dataset available.

Interestingly, only the WDM6 experiments (Figure 6b,f) seemed to adequately simulate the bright band in the outer rainbands.

Since radar observations located the most active area of Ianos in its southwestern quadrant and most of the simulations performed poorly at forecasting the northeastern part of the eyewall at $5 \mathrm{~km}$ height, Figure 7 shows the vertical cross-sections of the reflectivity for the SW-NE direction. The vertical profile crosses the eye for a length of $200 \mathrm{~km}$ for the simulations and $160 \mathrm{~km}$ for the observations, as shown in Figure $5 \mathrm{i}$ by the blue dashed line $\mathrm{B}$ (in the latter case, it is shorter on its southwestern side because it was out of the DPR swath field). The DPR vertical profile (Figure 7i) reveals that the most intense observed convection was located in the southwestern eyewall, with a reflectivity peak of $50.3 \mathrm{dBZ}$ around 3-4 km and values of $>42 \mathrm{dBZ}$ extending up to $5 \mathrm{~km}$, with cloud tops reaching about $11 \mathrm{~km}$. On the northeastern side of the eye, two stratiform rainbands can be identified, the one on the eyewall (exhibiting also the bright-band signature at a height of $3.5-4 \mathrm{~km}$ ) and an outer one with a lower vertical extension.

All experiments could reproduce reasonably well the southwestern high reflectivity eyewall region and approximate vertical extension. On the other hand, only the Thompson and Morrison schemes succeeded in predicting at least part, although of weaker intensity, of the northeastern eyewall and outer rainband. In particular, Thompson ECMWF appeared to be the only experiment that predicted a consistent northeastern eyewall, although it was still positioned too far relative to its medicane center.

Subsequently, in addition to the analyses of the single cross-section of radar reflectivity, we further exploited the DPR's vertical resolution by performing a more statistical analysis of the medicane's three-dimensional structure of the radar reflectivity field. This was achieved through the calculation of the contoured frequency by altitude diagrams (CFADs; [58]). Figure 8 shows the predicted $(\mathrm{a}-\mathrm{h})$ and observed (i) reflectivity frequencies binned every $2 \mathrm{dBZ}$, with a vertical resolution of $250 \mathrm{~m}$ within a radius of $200 \mathrm{~km}$ from the minimum MSLP center. The observed CFAD (Figure 8i) shows the maximum frequencies of $>8 \%$ in the $20-24 \mathrm{dBZ}$ bins at the height of $6-8 \mathrm{~km}$, with a sharp transition to very low frequencies at those levels with increasing reflectivity. The lack of significant occurrence of high reflectivities at high levels highlights, one more time, how the presence of heavy ice particles was negligible. In the lower levels of $1-3 \mathrm{~km}$, maximum frequencies of $\sim 5 \%$ were located in the 30-36 dBZ range, decreasing more smoothly (sharply) to lower (higher) reflectivities. At first glance, it is clear that the simulations were not able to simultaneously reproduce both frequency maxima observed in the higher and lower levels. However, they reasonably reproduced some of the features described above. They all showed a narrowing of the frequency distribution with height toward lower reflectivities, but with important differences. The Thompson and Morrison experiments overestimated both the vertical extent and the occurrence of high reflectivity values in the upper levels, especially in the case of Thompson (probably the result of excessive snow production, as mentioned earlier). On the other hand, WSM6 and WDM6 experiments tended to better describe the reflectivity ranges (18-26 dBZ) but underestimated the frequencies between 6 and $10 \mathrm{~km}$ (particularly in those GFS-based). At the same time, most simulations could reproduce to some extent the widening of the frequency distribution toward higher reflectivities around the height of $4 \mathrm{~km}$, a feature that was particularly well characterized by the WDM6 experiments. 


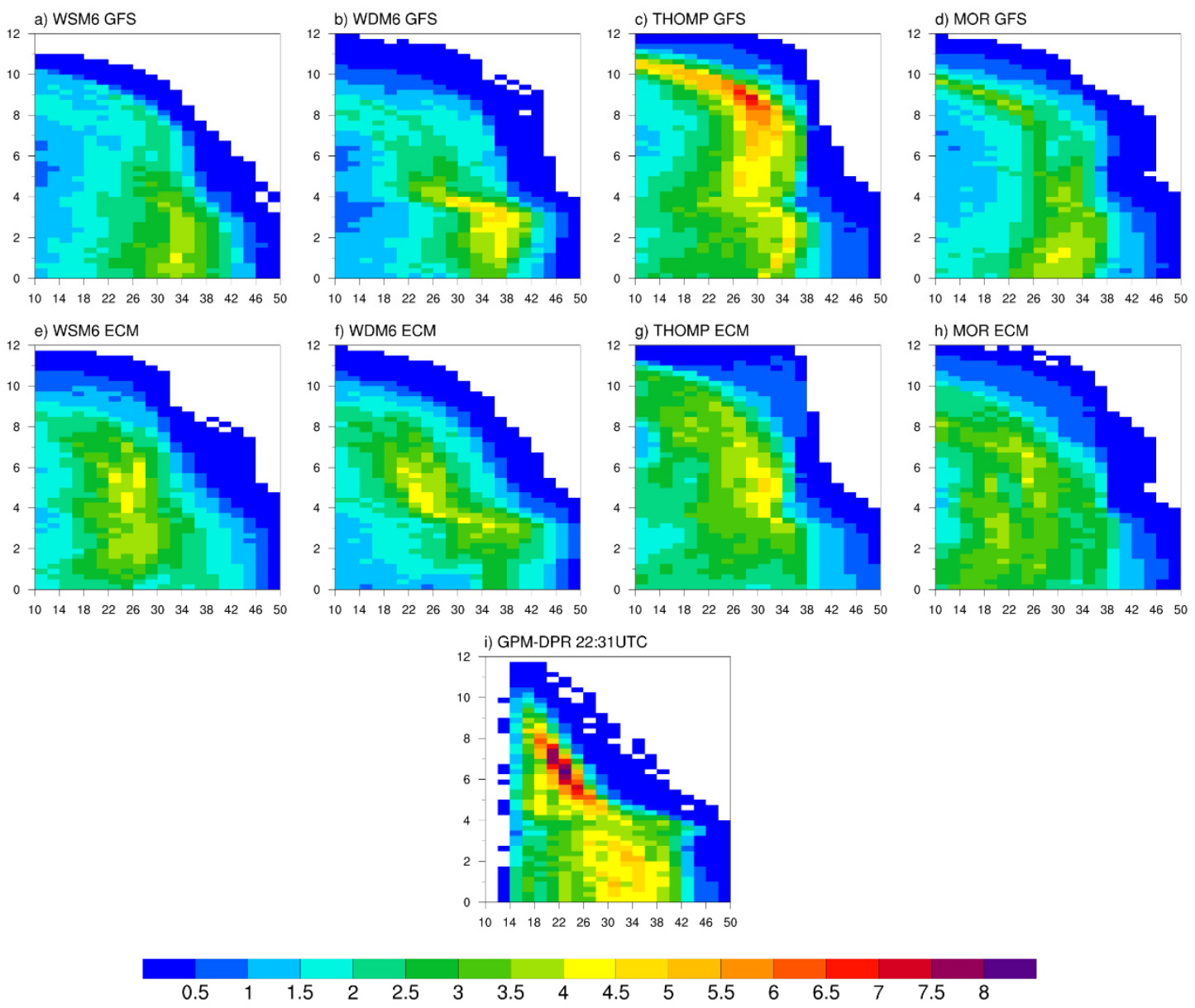

Figure 8. CFADs (in \%) of Ku-band radar corrected reflectivity (dBZ) at 10:30 p.m. UTC 17 September 2020 for all simulations (a-h) and as observed by the GPM-CO DPR overpass at 10:31 p.m. UTC (i) binned every 2 dBZ and every $250 \mathrm{~m}$ in height. The vertical axes are in $\mathrm{km}$.

In general, however, the ECMWF-based experiments showed more agreement with the observations in the middle levels $(4-6 \mathrm{~km})$ for reflectivities between 18 and $30 \mathrm{dBZ}$, which consistently exhibited at least one data point $>5 \%$ compared to none in the GFSbased simulations with the only exception of Thompson. Nevertheless, the former showed relatively wider frequency distributions at those levels compared to the DPR and to the GFSbased experiments, which could be partially attributed to the presence of snow and graupel, thus supporting the results for the integrated frozen hydrometeor content discussed in Figure 3b. Moreover, the ECMWF-based simulations reproduced more homogeneously the narrowing of the frequency distribution from middle to upper levels, with a more consistent slope, whereas the other simulations altogether displayed more variability in the reproduction of this feature. On the other hand, the GFS-based experiments showed better representation of the distribution in the lower levels (i.e., below $4 \mathrm{~km}$ ), especially in the 30-38 dBZ range.

Taken together, these results highlight the variability among the microphysical schemes tested here and the specificity inherent to each of them, while underlining the role of the IBCs in producing more realistic medicane microphysical features.

The integrated rainwater content of the simulations and as retrieved from the GPMCO DPR overpass is shown in Figure 9. The observations (Figure 9i) revealed an area with amounts as high as $\sim 24 \mathrm{~mm}$ in the main rainband west of the coasts of Lefkada and Kefalonia islands, a well-defined eyewall with some spots of high rainwater content, and a wide region with weak $(<1 \mathrm{~mm})$ values spreading north/northwest of the main rainband. The ECMWF-based simulations outperformed their GFS counterparts in terms of position 
and organization of these features, presenting a more evident eye-like shape and spiraling bands resembling more those present in the DPR observations. However, they all incurred a westward displacement bias in the medicane's position compared to the satellite retrieval. Moreover, especially for the inner region encompassing the eyewall, it is evident that their magnitudes were much closer to the observations, in line with the areal mean results exposed in Figure 3a.

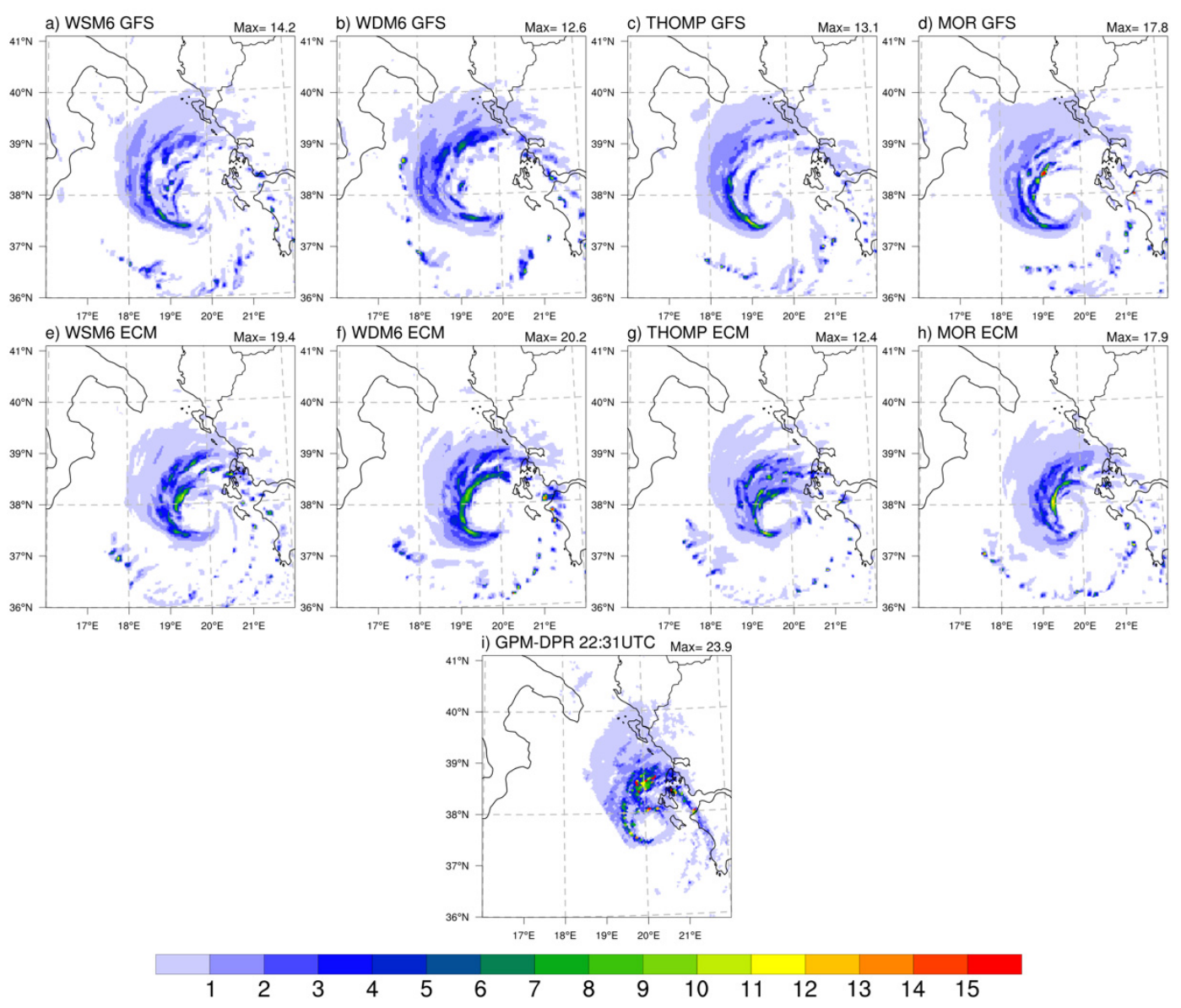

Figure 9. Integrated rainwater content (mm) at 10:30 p.m. UTC 17 September 2020 for all simulations (a-h) and as observed by the GPM-CO DPR overpass at 10:31 p.m. UTC (i).

It is interesting to note that, whereas, in the ECMWF-based simulations, the spatial location of the areas with moderate amounts of integrated rainwater content (and also of integrated frozen water content, not shown) tended to coincide with those of the simulated reflectivity at $5 \mathrm{~km}$ (Figure $5 \mathrm{e}-\mathrm{h}$ ), this was not always the case for the simulations with GFS. These exhibited some inner bands of integrated liquid water content around $19^{\circ} \mathrm{E}$ and $38-39^{\circ} \mathrm{N}$ (Figure $9 \mathrm{a}-\mathrm{d}$ ) in areas of complete absence of mid-level reflectivity (Figure 5a-d). This indicates, as also confirmed by the reduced height of the reflectivity cores in Figure $6 a-d$, the formation of very shallow convection that was not strong enough for the creation of neither significant frozen hydrometeors nor appreciable amounts of rain at middle levels.

Lastly, the DPR instantaneous precipitation rate at 10:31 p.m. UTC was compared with the simulation surface rain rate (calculated using the timestep precipitation provided by WRF) at 10:30 p.m. UTC, and the results are displayed in Figure 10. The DPR precipitation rate shown here (Figure 10i) corresponds to the height of $2 \mathrm{~km}$ in order to avoid the data gaps in lower altitudes due to the ground clutter. The observations showed intense rain rates (up to $\sim 76 \mathrm{~mm} \cdot \mathrm{h}^{-1}$ ) in spots around the eyewall and along the main spiraling rainbands, mostly north and northwest from the TLC center, while light rain $\left(<4 \mathrm{~mm} \cdot \mathrm{h}^{-1}\right)$ was present in the outer bands to the northwest and southeast of the eye, as well as in 
the southeastern portion of eyewall. Looking at the experiments, a better definition of the main observed rain rate characteristics can be seen for the ECMWF-based simulations, which developed a more accurate rain pattern in the eyewall and main rainbands to the north/northwest with respect to their GFS counterparts. Despite these differences, it is still noticeable that every microphysics scheme developed its own distinctive traits regardless of the global model employed. For instance, in all Thompson and Morrison experiments, the outer area of very light rain was quite extensive, whereas both WDM6 experiments produced almost no rain outside of the main rainbands and eyewall. Both WSM6 simulations predicted instead some more precipitation in those areas compared to WDM6. In addition, among the ECMWF-based experiments, it is remarkable that all except the WDM6 simulation were able to represent reasonably well (particularly Thompson) the surface precipitation in the main rainbands and in the well-defined eyewall region.

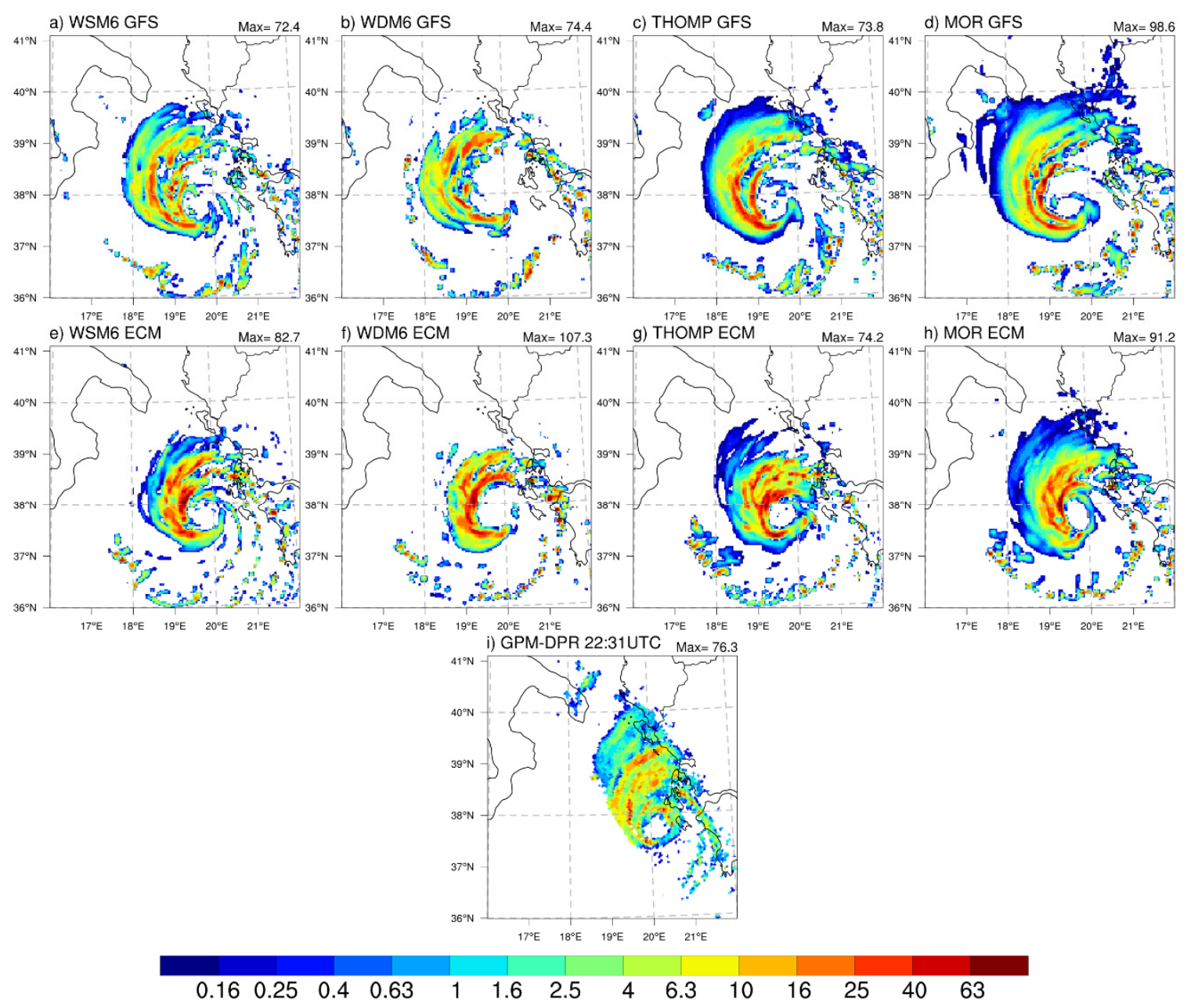

Figure 10. Instantaneous surface precipitation rate $\left(\mathrm{mm} \cdot \mathrm{h}^{-1}\right)$ at 10:30 p.m. UTC 17 September 2020 for all simulations (a-h) and as observed by the GPM-CO DPR overpass at 10:31 p.m. UTC (i) at $2 \mathrm{~km}$ above the sea level.

\subsection{Surface Wind Analysis with ASCAT}

The ASCAT scatterometer onboard the MetOp-C satellite made an overpass over the Ionian Sea at 7:11 p.m. UTC 17 September 2020 as Medicane Ianos was starting to impact the Western Greek islands. Its observed $10 \mathrm{~m}$ sea surface wind field is shown in Figure 11 alongside those from the model simulation outputs at 7:00 p.m. UTC, horizontally averaged to approximate the sensor resolution. The statistics were calculated by averaging the four model grid points nearest to every observation grid point contained within the area of $36-41^{\circ} \mathrm{N}$ and $16-22^{\circ} \mathrm{E}$, totaling a sampling size of $N=1471$. All experiments overestimated 
the maximum observed wind speed in the eyewall, while they underestimated the local minimum in the eye. It has to be highlighted that ASCAT, because of its low spatial resolution, could present difficulties in capturing the small eye features of Ianos. It is also true that the simulations were able to represent the low-level vortex with great precision and alignment in relation to that of the observations, as indicated by the high correlation coefficients $(r \geq 0.7)$ in the top right corner of every experiment panel. Nevertheless, the GFS experiments predicted stronger winds in the western quadrants of the TLC than their ECMWF counterparts, with RMSE values ranging between 4.3 and $5.1 \mathrm{~m} \cdot \mathrm{s}^{-1}$ and between 3.4 and $3.6 \mathrm{~m} \cdot \mathrm{s}^{-1}$, respectively. Furthermore, the simulations with ECMWF showed an $r$ value of $0.79-0.81$ compared with $0.70-0.76$ for GFS simulations.
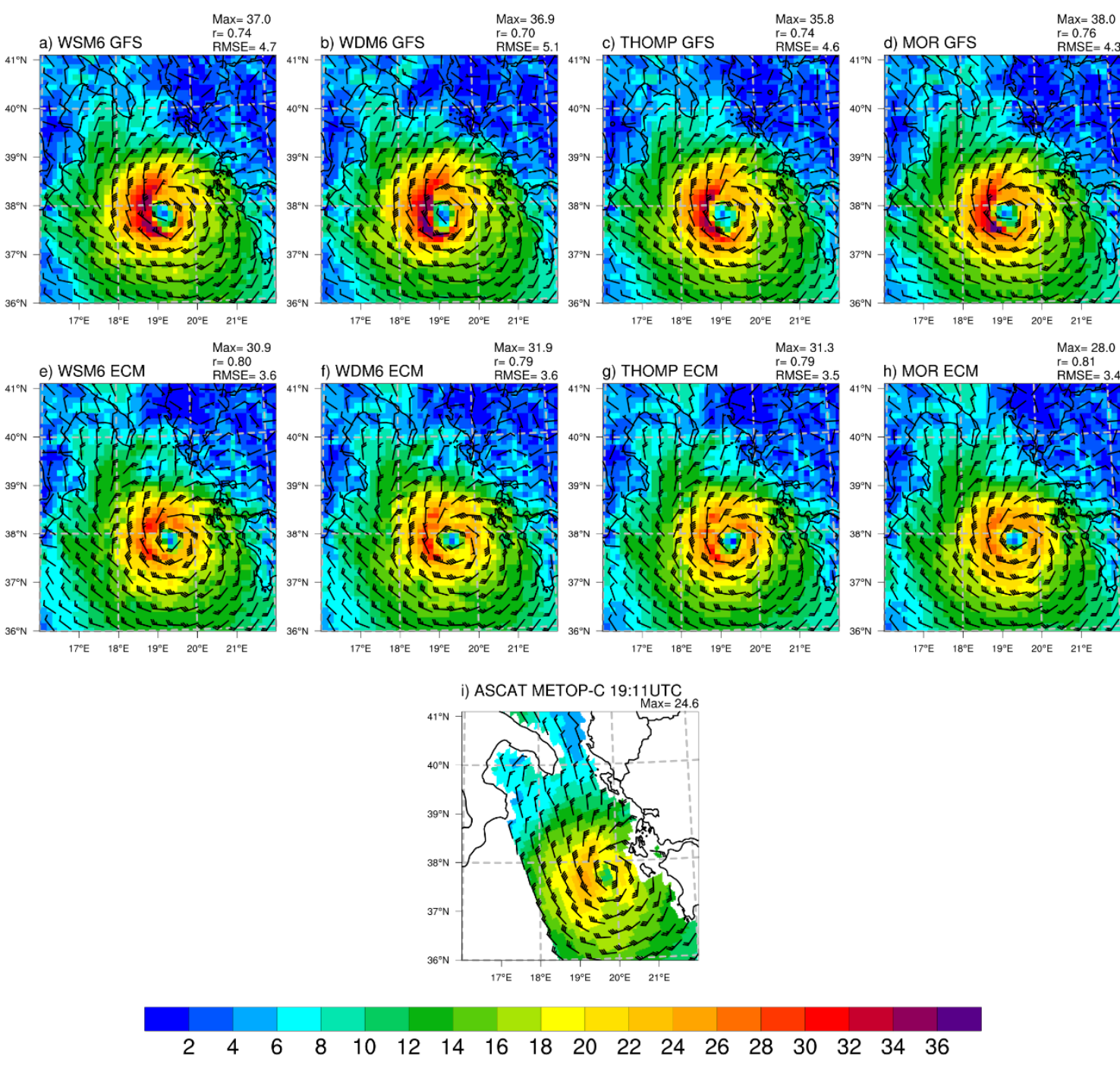

Figure 11. The $10 \mathrm{~m}$ wind direction (barbs in $\mathrm{kt}$ ) and speed (contours in $\mathrm{m} \cdot \mathrm{s}^{-1}$ ) at 7:00 p.m. UTC 17 September 2020 for all simulations (a-h) and as observed by the ASCAT MetOp-C overpass at 7:11 p.m. UTC (i). The simulated wind fields were averaged every four grid points in each horizontal direction to result in roughly the same horizontal resolution as the satellite product.

Among the different microphysics schemes, Morrison appeared to be the best in both global model groups considering $r$ and RMSE. Within the ECMWF group, the WDM6 and Thompson experiments were those that more accurately placed the bulk of the surface wind peak area in the southwestern quadrant of the medicane, similarly to the ASCAT observations. 


\section{Discussion and Conclusions}

In the present study, the sensitivity of the WRF model to microphysical schemes and IBCs in simulating the mature phase of Medicane Ianos (16-19 September 2020), one of the most powerful and destructive Mediterranean TLCs occured in recent years, was examined. Four different microphysical parameterizations of varying complexity and two global model datasets as IBCs were used for this purpose. The simulation results were compared against spaceborne precipitation radar observations and scatterometer sea surface winds. In particular, the GPM-CO DPR overpass at 10:31 p.m. UTC on 17 September captured the medicane during its TLC phase for the first time ever, right when Ianos was approaching the Ionian Greek islands, causing devastation and casualties. In the study, the GPM$\mathrm{CO}$ overpass was used to compare the simulated precipitation microphysics during the medicane mature phase with the DPR precipitation measurements, as well as to assess the simulations' ability to reproduce the observed precipitation pattern, intensity, and 3D structure.

The simulations with the WRF-ARW model were set to start at 12:00 p.m. UTC 17 September 2020 and were integrated until 12:00 a.m. UTC 18 September 2020, while TLC Ianos reached its maximum surface intensity of $\sim 995 \mathrm{hPa}$ about $3 \mathrm{~h}$ later (i.e., 3:00 a.m. UTC 18 September 2020) during its landfall over Western Greece. All simulations suffered from too much intensification of the surface pressure; however, those with ECMWF IBCs triggered more intense TLCs than those with GFS. It is important to note that WRF sensitivity to IBCs was caused by several factors that were not possible to separate with the dataset available. GFS and ECMWF models, indeed, have different physical schemes and dynamical cores, use different horizontal and vertical resolutions, have different assimilation schemes, and assimilate different observations.

In terms of the trajectories, no substantial differences were found among them. However, the variability of the minimum surface pressures among the different microphysics experiments was notable compared to that of their trajectories, which is a characteristic evidenced in previous studies of tropical cyclones [33]. The analyses of the cyclone phase space diagrams confirmed that all of the experiments were able to develop a deep warm core, and most of them also developed an axisymmetric structure, although this feature was present only at the start of the GFS-based simulations, and at the middle or end points in the majority of ECMWF-based experiments. However, we used the usual threshold of $B=10 \mathrm{~m}$ as a cutoff, whereas other studies [28] set it at a less stringent $15 \mathrm{~m}$. We used Hart's original parameters, originally proposed for tropical cyclones and adapted in previous studies $[7,59]$ to Mediterranean's midlatitude characteristics (lower tropopause than in the tropics) with more restrictive (lower) pressure level layers. It is worth noting that there were no observations to validate these results with higher precision.

The comparison between the radar reflectivity field as estimated by the simulations and as measured by the GPM-CO DPR revealed the better performance of the experiments with ECMWF data over those with GFS data. In fact, the former were able to accurately characterize the positions of the eyewall and/or the main rainband and outer bands at the low and middle levels, whereas the latter were not so successful in creating a well-defined eye, and they tended to place the main rainband too far in the northwest direction. However, both sets of simulations manifestly overestimated both the intensity of the reflectivity factor at mid-levels and the vertical extension of the clouds. These features were further supported through a more complete statistical analysis of the CFADs of the 3D reflectivity fields. Moreover, in the analysis of the NW-SE vertical cross-sections through the TLC eye, the ECMWF-based simulations showed large overestimations of the simulated reflectivity at low and middle levels at the northwestern eyewall and main spiraling rainband, evidencing the presence of convective cores where the observations detected only stratiform rain; this could explain why these simulations triggered stronger medicanes (i.e., lower minimum surface pressures) compared to their GFS-based counterparts. Nevertheless, most simulations failed to satisfactorily predict the northeastern quadrant of the eyewall, but all 
succeeded with the southwestern part. This was the most active area, as inferred from the observations, which exhibited some intense convective activity at low to middle levels.

It is known that the retrieval of the integrated frozen hydrometeor content from the DPR data is less reliable than that of rainwater; therefore, the analysis focused mainly on the surface rain rate and integrated rainwater content. The ECMWF-based simulations produced the most intense medicane while exhibiting substantially higher amounts of columnar precipitating ice (snow and graupel) than the GFS-based experiments, which further supports the idea that they promoted more vigorous vertical ascent and, therefore, lower surface pressures. In terms of the integrated rainwater, the ECMWF-based simulations showed values of similar magnitude to the observations, while the GFS-based experiments underestimated them.

The analysis of the ocean surface wind field from the ASCAT scatterometer overpass at 7:11 p.m. UTC 17 September revealed the best agreement among all the variables examined. All simulations exhibited great skill in surface wind intensity and organization, and they all adequately captured the spatial location of the TLC, despite a light shift to the west with respect to the observed position of the system. The experiments with ECMWF data clearly outperformed those with GFS data due to incurring less overestimation of the maximum wind speeds located in the southwestern quadrant of the eyewall.

Altogether, these results highlighted how the model was a bit more sensitive to the nature of the IBCs (spatial resolution and other dynamical and physical differences) than to the choice of microphysics parameterization scheme for this case of mature phase of the TLC Ianos. The higher spatial resolution (among other differences) of the ECMWF IBCs had a remarkable impact on the better definition of the main TLC's mesoscale features such as the low-level vortex, the creation of a consistent eyewall, and the positioning of the main and outer rainbands, which resulted in improved surface rain rate forecasts. At the same time, the simulations with the coarser IBCs turned out to be more skillful only at predicting a more realistic minimum surface pressure, but at the expense of a less accurate surface rain rate forecast because of their inappropriate characterization of the TLC's major mesoscale features.

We tested four microphysics schemes, all of which include the prognosis of the mass mixing ratios of the three main ice categories (i.e., ice, snow, and graupel). Only one was single-moment (WSM6), while the others were double-moment in varying degrees: the WDM6 included the number concentration prognosis for warm-rain processes (cloud and rainwater) only, the Thompson included the number concentration for rain and ice, and the Morrison scheme included that for rain and ice, snow, and graupel. As shown, the schemes that generally performed the best in the different fields analyzed were the Thompson and Morrison, especially in terms of the relative positioning and development of the primary mesoscale structures of the TLC such as the eyewall and main spiraling rainbands. This highlights, therefore, the important role of the accurate representation of the cloud ice processes in the microphysical parameterization for the correct forecast of Mediterranean TLCs. Nevertheless, it was found (e.g., the surface rain rate) that sometimes the WSM6 scheme, compared to the more complex WDM6, obtained better results despite being single-moment only, which means that using a more complex scheme does not always translate into improving the model performance. For these reasons, it would make sense to increasingly focus on operational TLC forecasting efforts using ensemble approaches, incorporating the multiple benefits of diverse but enriching microphysical parameterization schemes.

Last but not least, it is important to comment on the limitations of this study. It was designed to examine only the mature phase of TLC Ianos coinciding with the overpass of the GPM-CO DPR and MetOp-C ASCAT sensors. We focused on a relatively short lead time $(12 \mathrm{~h})$ forecast with $6 \mathrm{~h}$ considered as spin-up while the Ianos lifecycle was much longer. Furthermore, we tested just a few parameterization schemes within one of the physical categories, whereas it is known that, even if probably not as important as the microphysics, the PBL and surface layer parameterizations also play a prominent role in 
the correct model prediction of medicanes, according to several studies [27,29]. In spite of these limitations, this study was aimed at highlighting the key role of satellite observations (in particular, ASCAT surface winds and GPM precipitation measurements) in assessing the medicane forecast performance in terms of intensity and ability to reproduce the precipitation microphysics structure, especially offshore, where often no other wind or precipitation measurements are available. It is important to note that the comparison between the model microphysical output and the GPM-CO observations gave the opportunity to assess the performance of the microphysical schemes used in numerical models in simulating several aspects of the hydrometeors as their phases and dimensions. This gave the opportunity to have a deeper knowledge of the strengths and weaknesses of the different schemes and to refine the microphysical parameterizations of the models.

Lastly, we would like to make an open appeal to the community to consider making an official best track reanalysis product for medicanes, as we are sure it would have improved this study and would benefit many more in the future.

Author Contributions: Conceptualization, A.C.P., S.F. and G.P.; methodology, A.C.P., S.F., L.P.D. and G.P.; software, A.C.P., S.F., R.C.T. and L.P.D.; validation, A.C.P., S.F., R.C.T. and L.P.D.; investigation, A.C.P., S.F., L.P.D. and G.P.; data curation, A.C.P., S.F. and L.P.D.; writing-original draft preparation, A.C.P.; writing-review and editing, all authors; project administration, G.P. and S.D.; funding acquisition, S.D. All authors have read and agreed to the published version of the manuscript.

Funding: This work was partially funded by the Project PON ARS01 00405 OT4CLIMA Sviluppo di tecnologie innovative di Osservazione della Terra per lo studio del Cambiamento Climatico e dei suoi impatti sull'ambiente (Development of innovative Earth observation technologies for the study of climate change and its impacts on the environment), funded by the Italian Ministry of Education, University, and Research (MIUR) in the framework of the National Operational Program (PON) Research and Innovation 2014-2020, Specialization Area Aerospace.

Institutional Review Board Statement: Not applicable.

Informed Consent Statement: Not applicable.

Data Availability Statement: The WRF simulations outputs and GPM-CO DPR data can be requested from the authors. The ASCAT data can be found on the website https: / podaac.jpl.nasa.gov / dataset/ ASCATC-L2-Coastal (last accessed on 14 January 2021).

Acknowledgments: ECMWF and the Aeronautica Militare (Italian air force) are acknowledged for the use of MARS (Meteorological Archive and Retrieval System) database. The reviewers and the editor are acknowledged for their comments that improved the quality of the paper.

Conflicts of Interest: The authors declare no conflict of interest.

\section{References}

1. Ernst, J.A.; Matson, M. A Mediterranean Tropical Storm? Weather 1983, 38, 332-337. [CrossRef]

2. Rasmussen, E.; Zick, C. A subsynoptic vortex over the Mediterranean with some resemblance to polar lows. Tellus 1987, 39A, 408-425. [CrossRef]

3. Lagouvardos, K.; Kotroni, V.; Nickovic, S.; Jovic, D.; Kallos, G.; Tremback, C.J. Observations and model simulations of a winter sub-synoptic vortex over the central Mediterranean. Meteorol. Appl. 1999, 6, 371-383. [CrossRef]

4. Pytharoulis, I.; Craig, G.; Ballard, S. The hurricane-like Mediterranean cyclone of January 1995. Meteorl. Appl. 2000, 7, 261-279. [CrossRef]

5. Emanuel, K. Genesis and maintenance of "Mediterranean hurricanes". Adv. Geosci. 2005, 2, 217-220. [CrossRef]

6. Fita, L.; Romero, R.; Luque, A.; Emanuel, K.; Ramis, C. Analysis of the environments of seven Mediterranean tropical-like storms using an axisymmetric, nonhydrostatic, cloud resolving model. Nat. Hazards Earth Syst. Sci. 2007, 7, 41-56. [CrossRef]

7. Miglietta, M.M.; Laviola, S.; Malvaldi, A.; Conte, D.; Levizzani, V.; Price, C. Analysis of tropical-like cyclones over the Mediterranean Sea through a combined modeling and satellite approach. Geophys. Res. Lett. 2013, 40, 2400-2405. [CrossRef]

8. Dafis, S.; Claud, C.; Kotroni, V.; Lagouvardos, K.; Rysman, J. Insights into the convective evolution of Mediterranean tropical-like cyclones. Q. J. R. Meteorol. Soc. 2020, 146, 4147-4169. [CrossRef]

9. Reale, O.; Atlas, R. Tropical Cyclone Like Vortices in the Extratropics: Observational Evidence and Synoptic Analysis. Weather Forecast. 2001, 16, 7-34. [CrossRef] 
10. Moscatello, A.; Miglietta, M.M.; Rotunno, R. Observational analysis of a Mediterranean 'hurricane' over south-eastern Italy. Weather 2008, 63, 306-311. [CrossRef]

11. Michaelides, S.; Karacostas, T.; Sánchez, J.L.; Retalis, A.; Pytharoulis, I.; Homar, V.; Romero, R.; Zanis, P.; Giannakopoulos, C.; Bühl, J.; et al. Reviews and perspectives of high impact atmospheric processes in the Mediterranean. Atmos. Res. 2018, $208,4-44$. [CrossRef]

12. Cavicchia, L.; von Storch, H.; Gualdi, S. A long-term climatology of medicanes. Clim. Dyn. 2014, 43, 1183-1195. [CrossRef]

13. Nastos, P.T.; Papadimou, K.K.; Matsangouras, I.T. Mediterranean tropical-like cyclones: Impacts and composite daily means and anomalies of synoptic patterns. Atmos. Res. 2018, 206, 156-166. [CrossRef]

14. Romero, R.; Emanuel, K. Medicane risk in a changing climate. J. Geophys. Res. Atmos. 2013, 118, 5992-6001. [CrossRef]

15. González-Alemán, J.J.; Pascale, S.; Gutierrez-Fernandez, J.; Murakami, H.; Gaertner, M.A.; Vecchi, G.A. Potential increase in hazard from Mediterranean hurricane activity with global warming. Geophys. Res. Lett. 2019, 46, 1754-1764. [CrossRef]

16. Homar, V.; Romero, R.; Stensrud, D.J.; Ramis, C.; Alonso, S. Numerical diagnosis of a small, quasi-tropical cyclone over the western Mediterranean: Dynamical vs. boundary factors. Q. J. R. Meteorol. Soc. 2003, 129, 1469-1490. [CrossRef]

17. Miglietta, M.M.; Moscatello, A.; Conte, D.; Mannarini, G.; Lacorata, G.; Rotunno, R. Numerical analysis of a Mediterranean 'hurricane' over south-eastern Italy: Sensitivity experiments to sea surface temperature. Atmos. Res. 2011, 101, 412-426. [CrossRef]

18. Chaboureau, J.P.; Pantillon, F.; Lambert, D.; Richard, E.; Claud, C. Tropical transition of a Mediterranean storm by jet crossing. Q. J. R. Meteorol. Soc. 2012, 138, 596-611. [CrossRef]

19. Carrió, D.S.; Homar, V.; Jansa, A.; Romero, R.; Picornell, M.A. Tropicalization process of the 7 November 2014 Mediterranean cyclone: Numerical sensitivity study. Atmos. Res. 2017, 197, 300-312. [CrossRef]

20. Emanuel, K.A. An Air-Sea Interaction Theory for Tropical Cyclones. Part I: Steady-State Maintenance. J. Atmos. Sci. 1986, 43, 585-605. [CrossRef]

21. Cioni, G.; Malguzzi, P.; Buzzi, A. Thermal structure and dynamical precursor of a Mediterranean tropical-like cyclone. Q. J. R. Meteorol. Soc. 2016, 142, 1757-1766. [CrossRef]

22. Miglietta, M.M.; Cerrai, D.; Laviola, S.; Cattani, E.; Levizzani, V. Potential vorticity patterns in Mediterranean "hurricanes". Geophys. Res. Lett. 2017, 44, 2537-2545. [CrossRef]

23. Mazza, E.; Ulbrich, U.; Klein, R. The Tropical Transition of the October 1996 Medicane in the Western Mediterranean Sea: A Warm Seclusion Event. Mon. Weather Rev. 2017, 145, 2575-2595. [CrossRef]

24. Miglietta, M.M.; Rotunno, R. Development mechanisms for Mediterranean tropical-like cyclones (medicanes). Q. J. R. Meteorol. Soc. 2019, 145, 1444-1460. [CrossRef]

25. Davolio, S.; Miglietta, M.M.; Moscatello, A.; Pacifico, F.; Buzzi, A.; Rotunno, R. Numerical forecast and analysis of a tropical-like cyclone in the Ionian Sea. Nat. Hazards Earth Syst. Sci. 2009, 9, 551-562. [CrossRef]

26. Miglietta, M.M.; Mastrangelo, D.; Conte, D. Influence of physics parameterization schemes on the simulation of a tropical-like cyclone in the Mediterranean Sea. Atmos. Res. 2015, 153, 360-375. [CrossRef]

27. Pytharoulis, I.; Kartsios, S.; Tegoulias, I.; Feidas, H.; Miglietta, M.; Matsangouras, I.; Karacostas, T. Sensitivity of a Mediterranean Tropical-Like Cyclone to Physical Parameterizations. Atmosphere 2018, 9, 436. [CrossRef]

28. Mylonas, M.P.; Douvis, K.C.; Polychroni, I.D.; Politi, N.; Nastos, P.T. Analysis of a Mediterranean Tropical-Like Cyclone. Sensitivity to WRF Parameterizations and Horizontal Resolution. Atmosphere 2019, 10, 425. [CrossRef]

29. Ricchi, A.; Miglietta, M.M.; Barbariol, F.; Benetazzo, A.; Bergamasco, A.; Bonaldo, D.; Cassardo, C.; Falcieri, F.M.; Modugno, G.; Russo, A.; et al. Sensitivity of a Mediterranean Tropical-Like Cyclone to Different Model Configurations and Coupling Strategies. Atmosphere 2017, 8, 92. [CrossRef]

30. Ragone, F.; Mariotti, M.; Parodi, A.; von Hardenberg, J.; Pasquero, C. A Climatological Study of Western Mediterranean Medicanes in Numerical Simulations with Explicit and Parameterized Convection. Atmosphere 2018, 9, 397. [CrossRef]

31. Zhu, T.; Zhang, D.-L. Numerical simulation of Hurricane Bonnie (1998). Part II: Sensitivity to varying cloud microphysical processes. J. Atmos. Sci. 2006, 63, 109-126. [CrossRef]

32. Li, X.; Pu, Z. Sensitivity of numerical simulation of early rapid intensification of hurricane Emily (2005) to cloud microphysical and planetary boundary layer parameterization. Mon. Weather Rev. 2008, 136, 4819-4838. [CrossRef]

33. Tao, W.K.; Shi, J.J.; Chen, S.S.; Lang, S.; Lin, P.L.; Hong, S.Y.; Peters-Lidard, C.; Hou, A. The impact of microphysical schemes on hurricane intensity and track. Asia-Pac. J. Atmos. Sci. 2011, 47, 1-16. [CrossRef]

34. Hou, A.Y.; Kakar, R.K.; Neeck, S.; Azarbarzin, A.A.; Kummerow, C.D.; Kojima, M.; Oki, R.; Nakamura, K.; Iguchi, T. The Global Precipitation Measurement Mission. Bull. Am. Meteorol. Soc. 2014, 95, 701-722. [CrossRef]

35. Skofronick-Jackson, G.; Petersen, W.A.; Berg, W.; Kidd, C.; Stocker, E.F.; Kirschbaum, D.B.; Kakar, R.; Braun, S.A.; Huffman, G.J.; Iguchi, T.; et al. The Global Precipitation Measurement (GPM) Mission for Science and Society. Bull. Am. Meteorol. Soc. 2017, 98, 1679-1695. [CrossRef]

36. Panegrossi, G.; Casella, D.; Dietrich, S.; Marra, A.C.; Sano, P.; Mugnai, A.; Baldini, L.; Roberto, N.; Adirosi, E.; Cremonini, R.; et al. Use of the GPM Constellation for Monitoring Heavy Precipitation Events over the Mediterranean Region. IEEE J. Sel. Top. Appl. Earth Obs. Remote Sens. 2016, 9, 2733-2753. [CrossRef]

37. Panegrossi, G.; Marra, A.C.; Sanò, P.; Baldini, L.; Casella, D.; Porcù, F. Heavy precipitation systems in the Mediterranean area: The role of GPM. In Satellite Precipitation Measurement; Levizzani, V., Kidd, C., Kirschbaum, D.B., Kummerow, C.D., Nakamura, K., Turk, F.J., Eds.; Springer: Dordrecht, The Netherlands, 2019. 
38. Marra, A.C.; Porcù, F.; Baldini, L.; Petracca, M.; Casella, D.; Dietrich, S.; Mugnai, A.; Sanò, P.; Vulpiani, G.; Panegrossi, G. Observational analysis of an exceptionally intense hailstorm over the Mediterranean area: Role of the GPM Core Observatory. Atmos. Res. 2017, 192, 72-90. [CrossRef]

39. Marra, A.C.; Federico, S.; Montopoli, M.; Avolio, E.; Baldini, L.; Casella, D.; D'Adderio, L.P.; Dietrich, S.; Sanò, P.; Torcasio, R.C.; et al. The Precipitation Structure of the Mediterranean Tropical-Like Cyclone Numa: Analysis of GPM Observations and Numerical Weather Prediction Model Simulations. Remote Sens. 2019, 11, 1690. [CrossRef]

40. Zekkos, D.; Zalachoris, G.; Alvertos, A.E.; Amatya, P.M.; Blunts, P.; Clark, M.; Dafis, S.; Farmakis, I.; Ganas, A.; Hille, M.; et al. The September 18-20 2020 Medicane Ianos Impact on Greece-Phase I Reconnaissance Report. Geotechnical Extreme Events Reconnaissance Report, GEER-068. Available online: http:/ /geerassociation.org/administrator/components/com_geer_reports/ geerfiles/Medicane\%20Ianos\%20GEER\%20Report.pdf (accessed on 7 December 2021).

41. Seto, S.; Iguchi, T.; Oki, T. The Basic Performance of a Precipitation Retrieval Algorithm for the Global Precipitation Measurement Mission's Single/Dual-Frequency Radar Measurements. IEEE Trans. Geosci. Remote Sens. 2013, 51, 5239-5251. [CrossRef]

42. MetOp-C ASCAT Level 2 Ocean Surface Wind Vectors Optimized for Coastal Ocean. Ver. Operational/Near-Real-Time. PO.DAAC, CA, USA. Available online: https:/ / podaac.jpl.nasa.gov/dataset/ASCATC-L2-Coastal (accessed on 14 January 2021).

43. Skamarock, W.C.; Klemp, J.B.; Dudhia, J.; Gill, D.O.; Liu, Z.; Berner, J.; Wang, W.; Powers, J.G.; Duda, M.G.; Barker, D.M.; et al. A Description of the Advanced Research WRF Version 4; No. NCAR/TN-556+STR, NCAR Technical Note; National Center for Atmospheric Research: Boulder, CO, USA, 2019; 145p.

44. Hong, S.-Y.; Lim, J.-O.J. The WRF single-moment 6-class microphysics scheme (WSM6). J. Korean Meteor. Soc. 2006, 42, $129-151$.

45. Lim, K.-S.S.; Hong, S.-Y. Development of an effective double-moment cloud microphysics scheme with prognostic cloud condensation nuclei (CCN) for weather and climate models. Mon. Weather Rev. 2010, 138, 1587-1612. [CrossRef]

46. Thompson, G.; Field, P.R.; Rasmussen, R.M.; Hall, W.D. Explicit forecasts of winter precipitation using an improved bulk microphysics scheme. Part II: Implementation of a new snow parameterization. Mon. Weather Rev. 2008, 136, 5095-5115. [CrossRef]

47. Morrison, H.; Thompson, G.; Tatarskii, V. Impact of cloud microphysics on the development of trailing stratiform precipitation in a simulated squall line: Comparison of one- and two-moment schemes. Mon. Weather Rev. 2008, 137, 991-1007. [CrossRef]

48. Hong, S.-Y.; Noh, Y.; Dudhia, J. A new vertical diffusion package with an explicit treatment of entrainment processes. Mon. Weather Rev. 2006, 134, 2318-2341. [CrossRef]

49. Jiménez, P.A.; Dudhia, J.; González-Rouco, J.F.; Navarro, J.; Montávez, J.P.; García-Bustamante, E. A Revised Scheme for the WRF Surface Layer Formulation. Mon. Weather Rev. 2012, 140, 898-918. [CrossRef]

50. Chen, F.; Dudhia, J. Coupling an advanced land surface-hydrology model with the Penn State-NCAR MM5 modeling system. Part I: Model implementation and sensitivity. Mon. Weather Rev. 2001, 129, 569-585. [CrossRef]

51. Dudhia, J. Numerical study of convection observed during the Winter Monsoon Experiment using a mesoscale two-dimensional model. J. Atmos. Sci. 1989, 46, 3077-3107. [CrossRef]

52. Mlawer, E.J.; Taubman, S.J.; Brown, P.D.; Iacono, M.J.; Clough, S.A. Radiative transfer for inhomogeneous atmosphere: RRTM, a validated correlated-k model for the longwave. J. Geophys. Res. 1997, 102D, 16663-16682. [CrossRef]

53. Hart, R.E. A Cyclone Phase Space Derived from Thermal Wind and Thermal Asymmetry. Mon. Weather Rev. 2003, 131, 585-616. [CrossRef]

54. Pytharoulis, I. Analysis of a Mediterranean tropical-like cyclone and its sensitivity to the sea surface temperatures. Atmos. Res. 2018, 208, 167-179. [CrossRef]

55. Tous, M.; Romero, R. Meteorological environments associated with medicane development. Int. J. Climatol. 2013, 33, 1-14. [CrossRef]

56. Copernicus Marine Services. Available online: https://resources.marine.copernicus.eu (accessed on 20 January 2021).

57. Medicane over Ionian Sea Causes Storms in Italy and Greece. Available online: https://www.eumetsat.int/medicane-overionian-sea-causes-storms-italy-and-greece (accessed on 20 January 2021).

58. Yuter, S.E.; Houze, R.A. Three-dimensional kinematic and microphysical evolution of Florida cumulonimbus. Part II: Frequency distributions of vertical velocity, reflectivity, and differential reflectivity. Mon. Weather Rev. 1995, 123, 1941-1963. [CrossRef]

59. Picornell, M.A.; Campins, J.; Jansà, A. Detection and thermal description of medicanes from numerical simulation. Nat. Hazards Earth Syst. Sci. 2014, 14, 1059-1070. [CrossRef] 